\title{
Characterization of core extracted from the Olmos Formation (Cretaceous), Southwest Texas
}

Alex W. Karlsen, Peter D. Warwick, Robert W. Hook*, J ohn R. SanFilipo ,Charles E. Barker,J ennifer M. Klein*

U.S. Geological Survey, Reston, VA

U.S. Geological Survey, Denver, CO

${ }^{*}$ Contractor to the U.S. Geological Survey

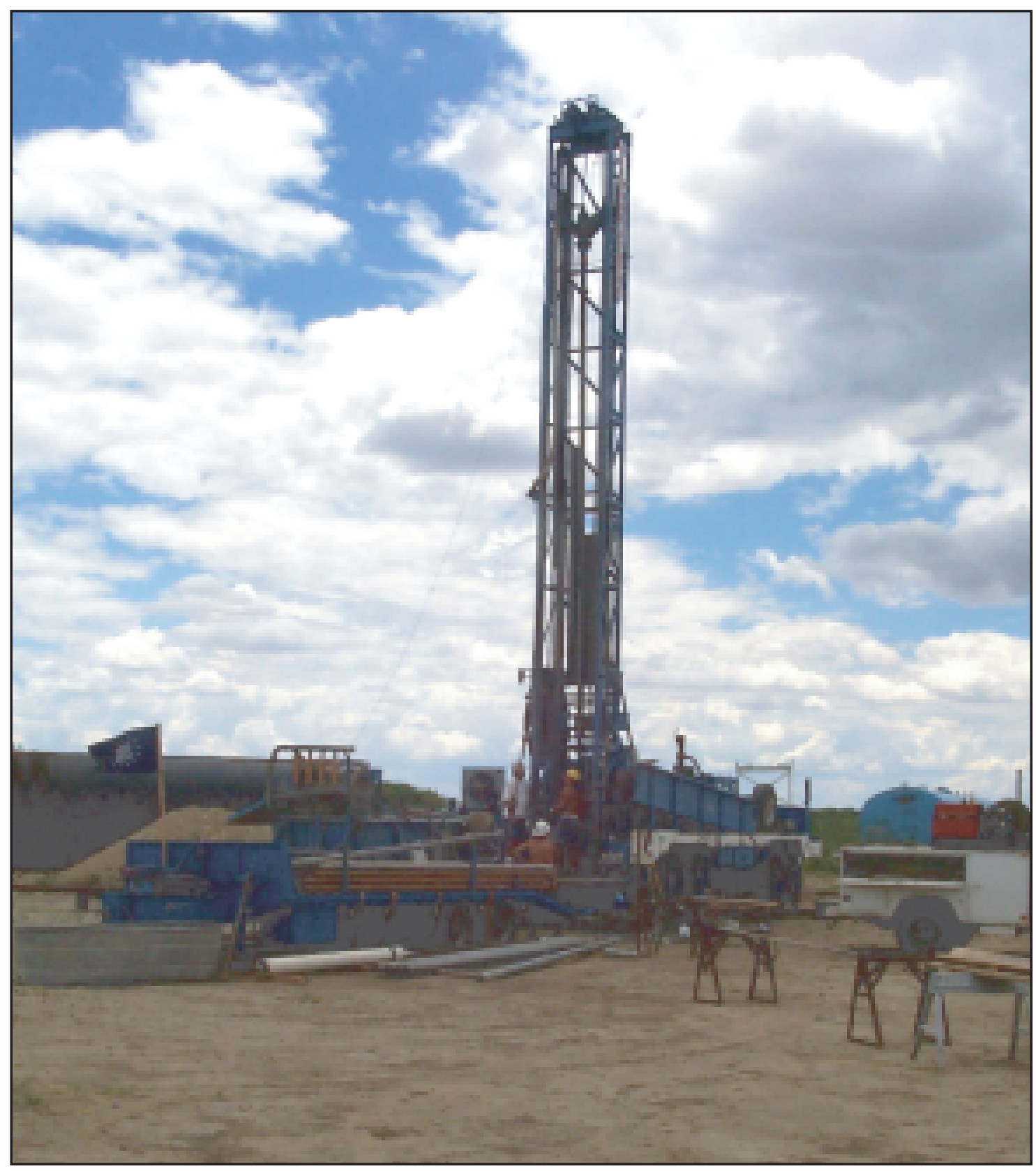

\section{U.S. Geological Survey Open-File Report 02-417}




\section{INTRODUCTION}

This preliminary report presents data from ongoing activities of the U.S. Geological Survey (USGS), Energy Resources Program, Gulf Coast Framework Studies Project (GCFSP). The purpose of the GCFSP is to conduct geologic framework studies that will aid in the evaluation of all fossil fuel energy commodities (coal, gas, and oil) in the Gulf Coast Region. The project will: (1) define the petroleum systems of the region; (2) conduct specific geologic framework studies and petroleum system analyses on selected priority intervals; (3) study the coal-bearing intervals to evaluate coal distribution and quality, and coal-bed methane, and source rock potential; (4) work in cooperation with the National Oil and Gas Assessment (NOGA) Project to conduct a focused assessment of the Gulf Region; and (5) contribute to the next phase of the National Coal Resource Assessment.

The USGS, through a Cooperative Research and Development Agreement (CRADA) with The Exploration Company (TXCO) of San Antonio, has drilled a series of wells to assess the coalbed methane potential in the South Texas portion of the Gulf Coast Region. This report presents lithologic descriptions, photographs, and $\mathrm{x}$-ray prints of cored intervals from the Olmos Formation (Cretaceous) from two wells, 1-117CR and 1-613CR, located in Maverick County (Figure 1). The cored interval for 1117 CR (from 1090.0 feet to 1212.5 feet below the surface) is 122.5 feet in length. For the 1-613CR well, the cored interval (from 1390.0 feet to 1525.7 feet below the surface) is 135.7 feet in length. The depths and lithology thicknesses for 1-117CR and 1-613CR were corrected based on comparison with borehole e-logs from the well locations. Due to depth correction of intervals for 1-613CR, information on cardboard or wood block labeled markers used in the core photographs to denote portions of the cores that were removed or missing, at the time of photography, do not reflect the corrected depth intervals.

X-ray radiographs were taken of the coal and carbonaceous shale portions of the cores to determine internal structural properties such as, partings, cleats, and burrows. For conversion to digital format the x-ray prints were scanned and, as a result, they appear as reversed images in this report.

Additionally, in the scanned $\mathrm{x}$-ray prints, carbonaceous shales or clays appear white and coals are black.

Initial analyses of sample data from cores 1-117CR and 1-613CR show average as-received ash yield values of 61.09 percent and 58.94 percent, respectively. Less than 50 percent ash yield occurs for five of the samples from 1-117CR and four of the samples from 1-613CR. Based on these initial results, intervals described as coal in 1-117CR and 1-613CR, in some cases, would be classified as carbonaceous shales and not coal (Wood and others, 1981).

\section{REFERENCES}

Wood,G.H. and others. 1983, Coal resource classification system of the U.S. Geological Survey: U.S. Geological Survey Circular 891, 65 p.

\section{ACKNOWLEDGEMENTS}

We wish to acknowledge The Exploration Company for their continuing assistance and collaboration. The radiographs were performed with the assistance of Jeff Halka and William Panageotou of the Maryland Geological Survey and we would like to thank them for their cooperation in this study. In addition, we wish to acknowledge Bryan Williams of Stata Log for his assistance in the field. 


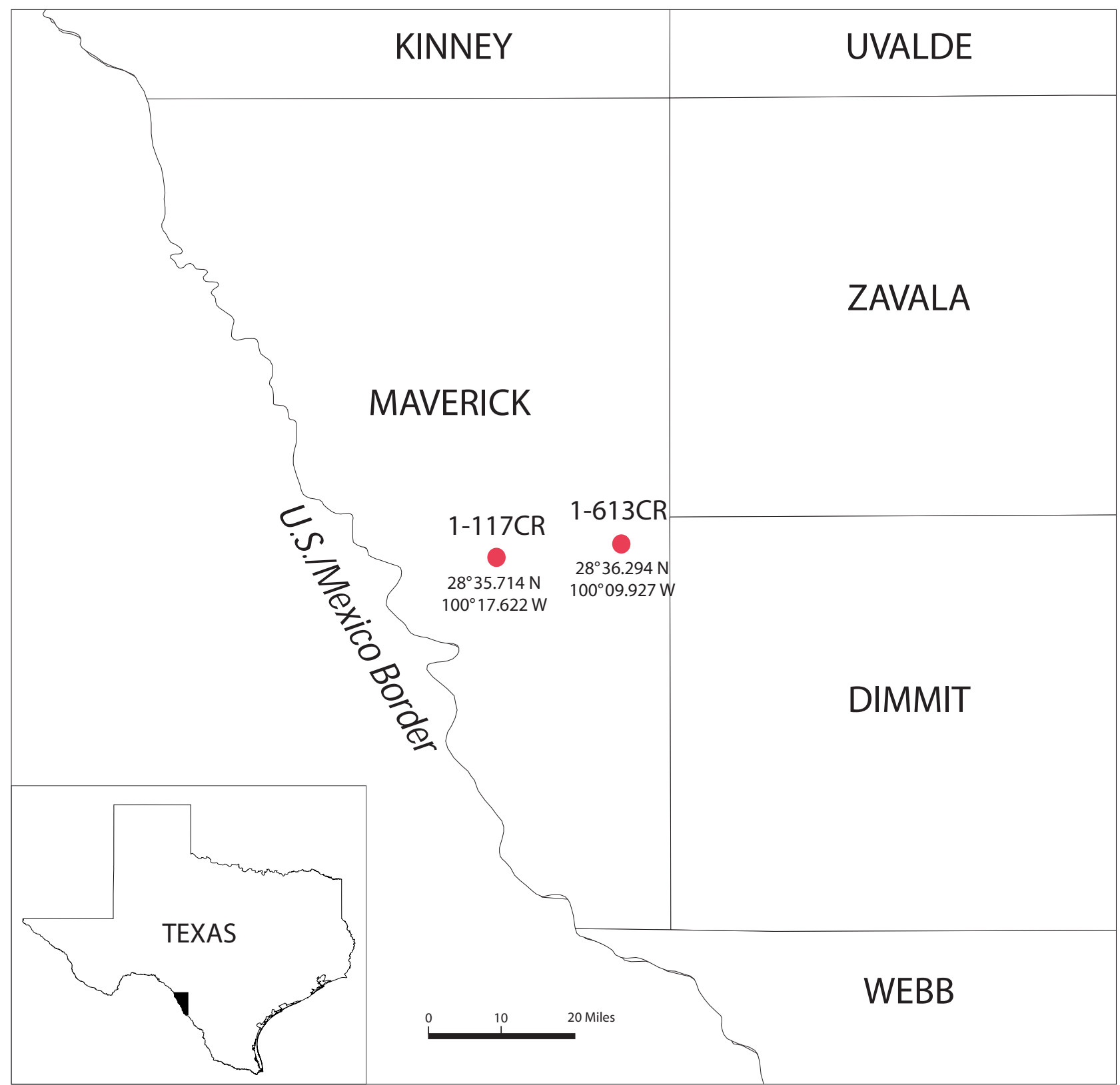

Figure 1. Locations of drill holes (red circles) in Maverick County, Texas. Click on the drill hole locations for core stratigraphy, photographs, and x-ray radiographs 


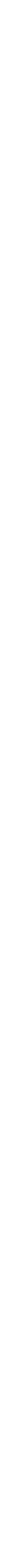




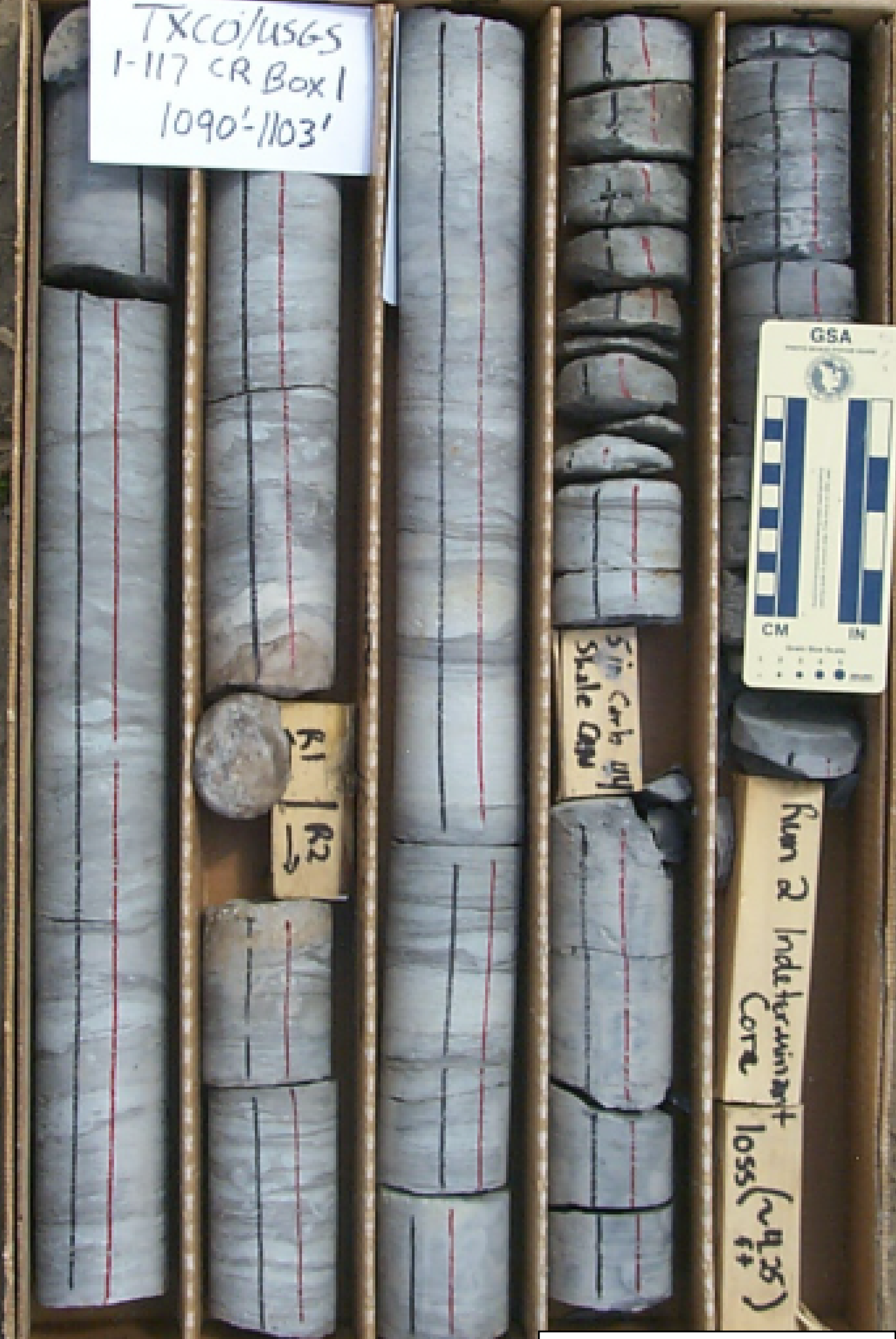




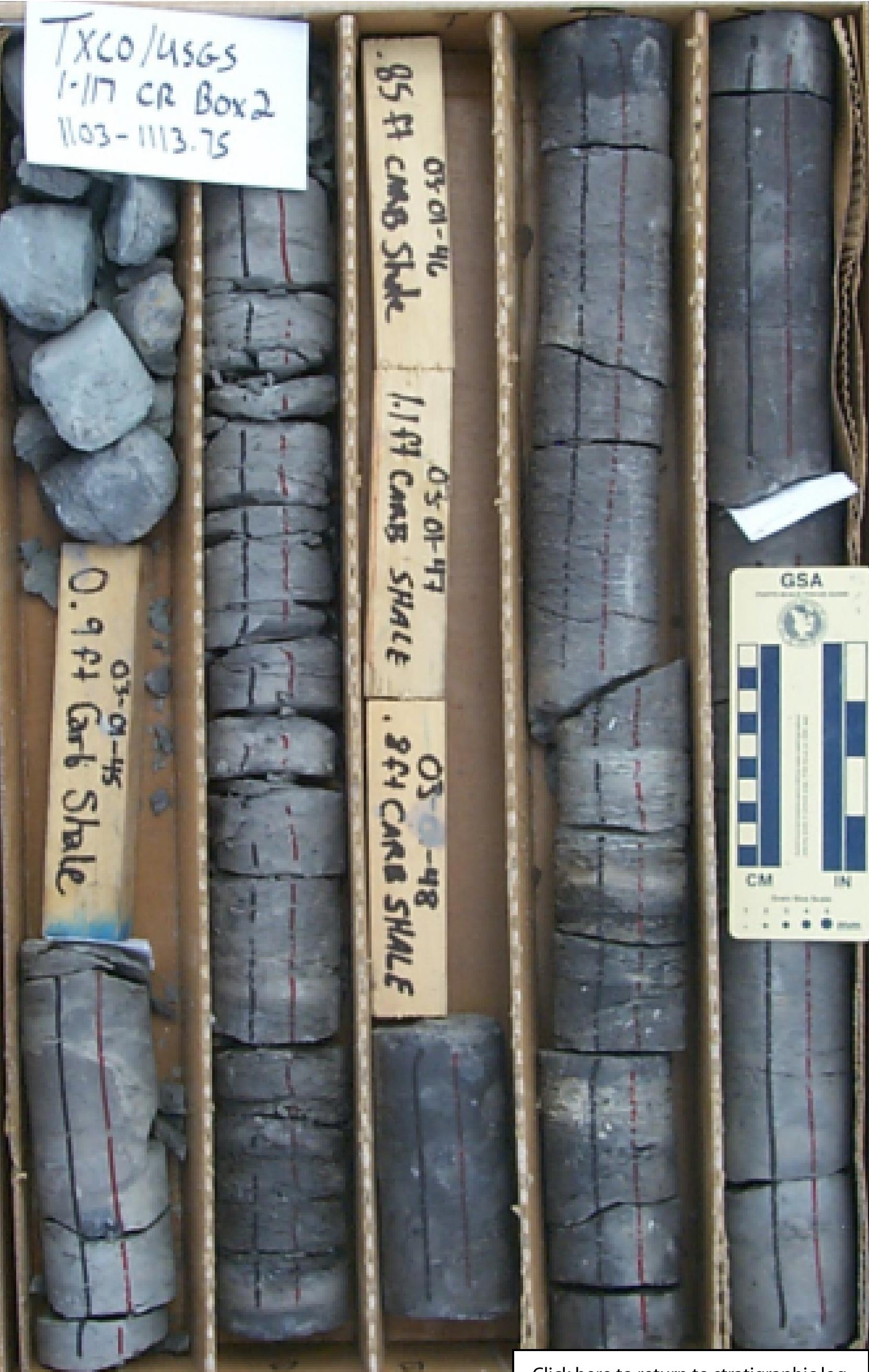




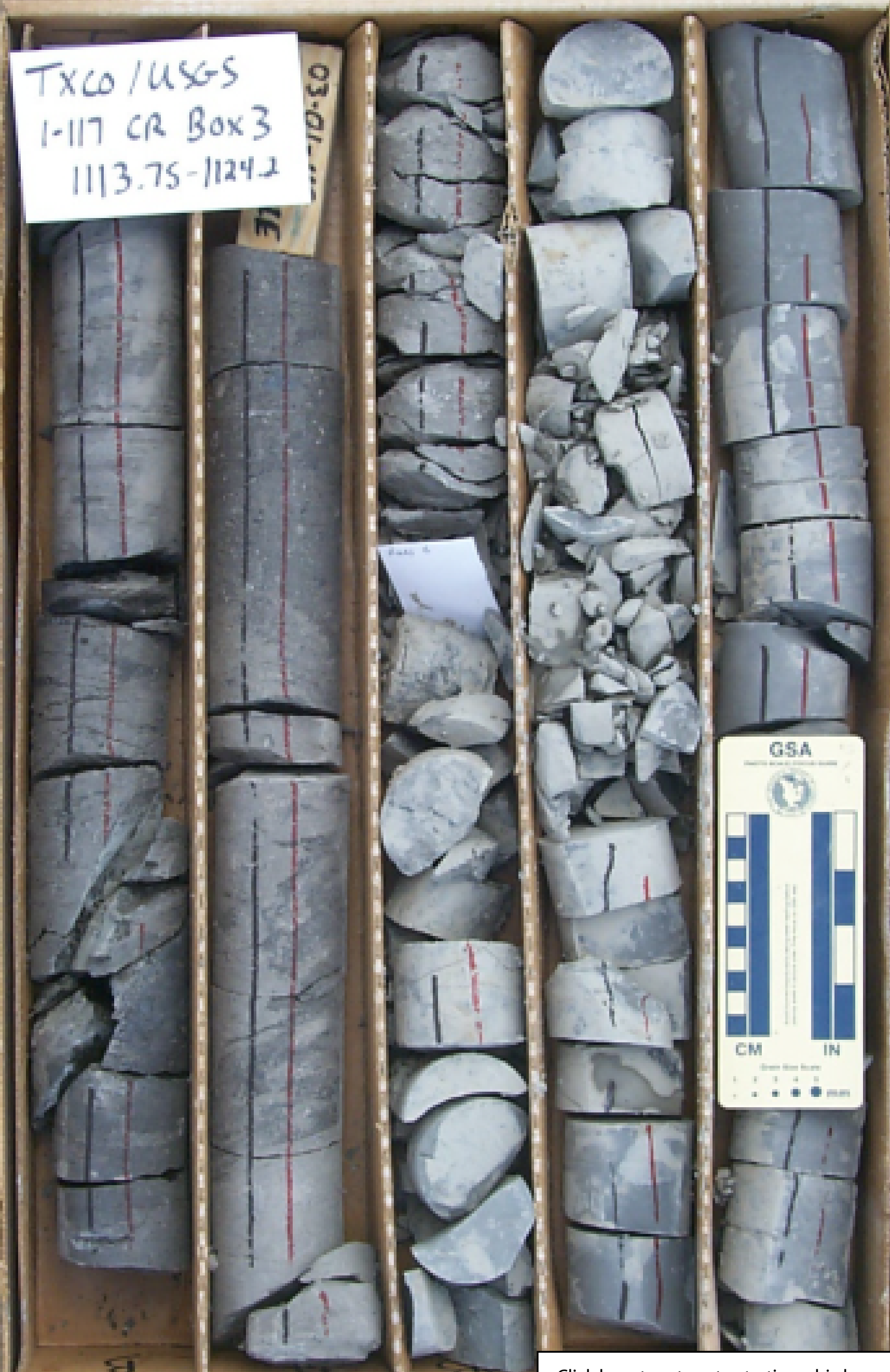




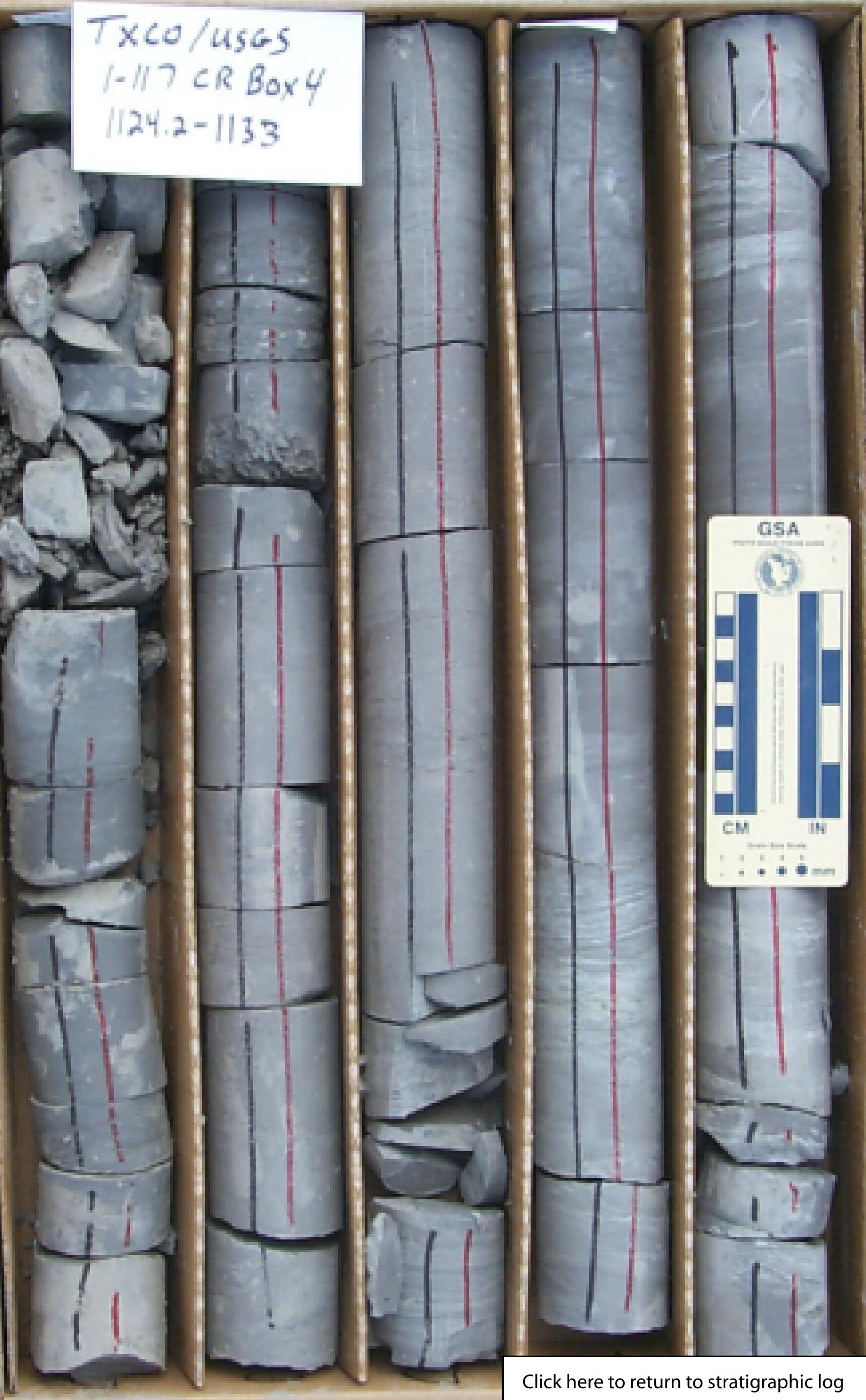




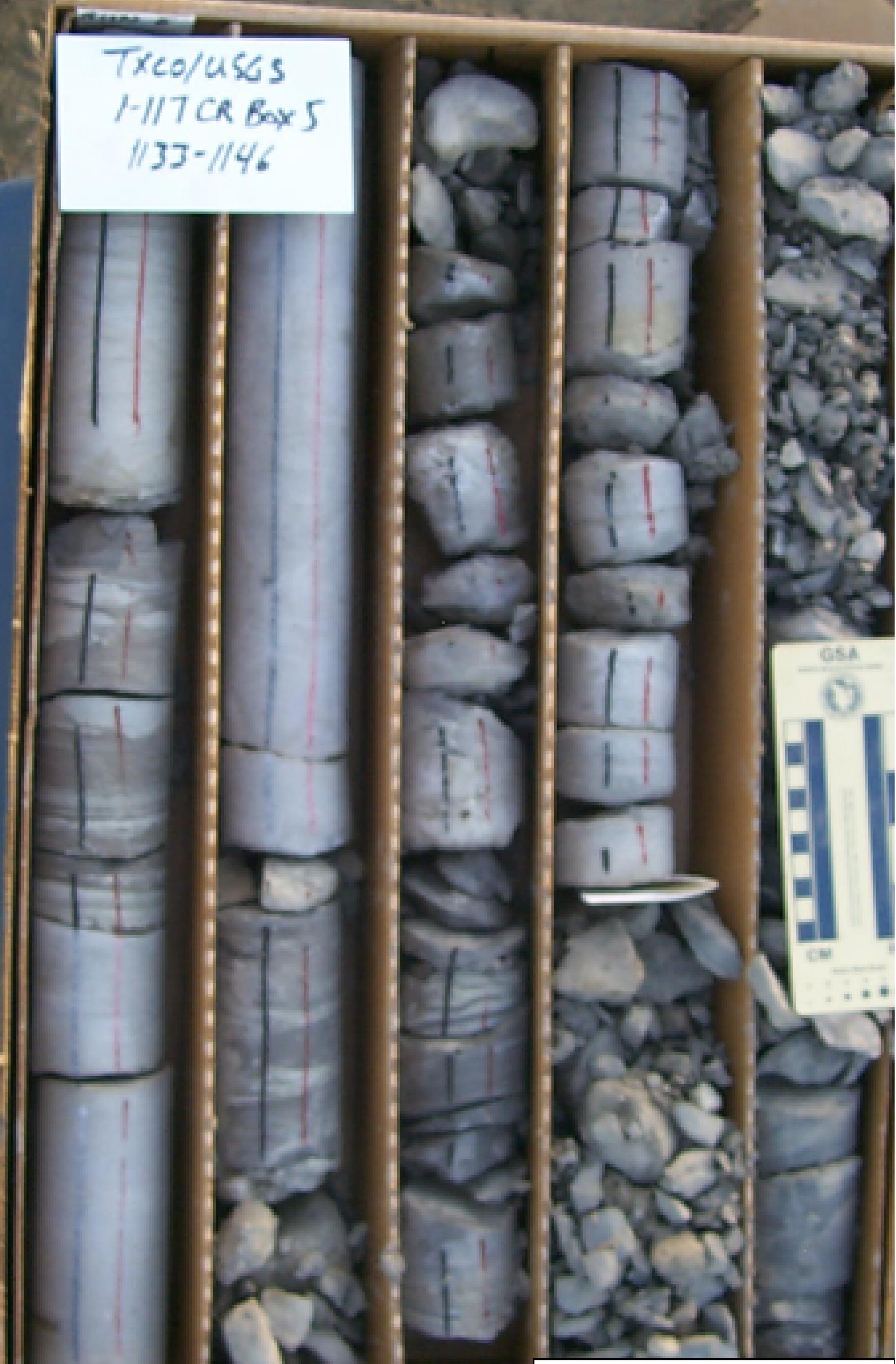

Click here to return to stratigraphic log 



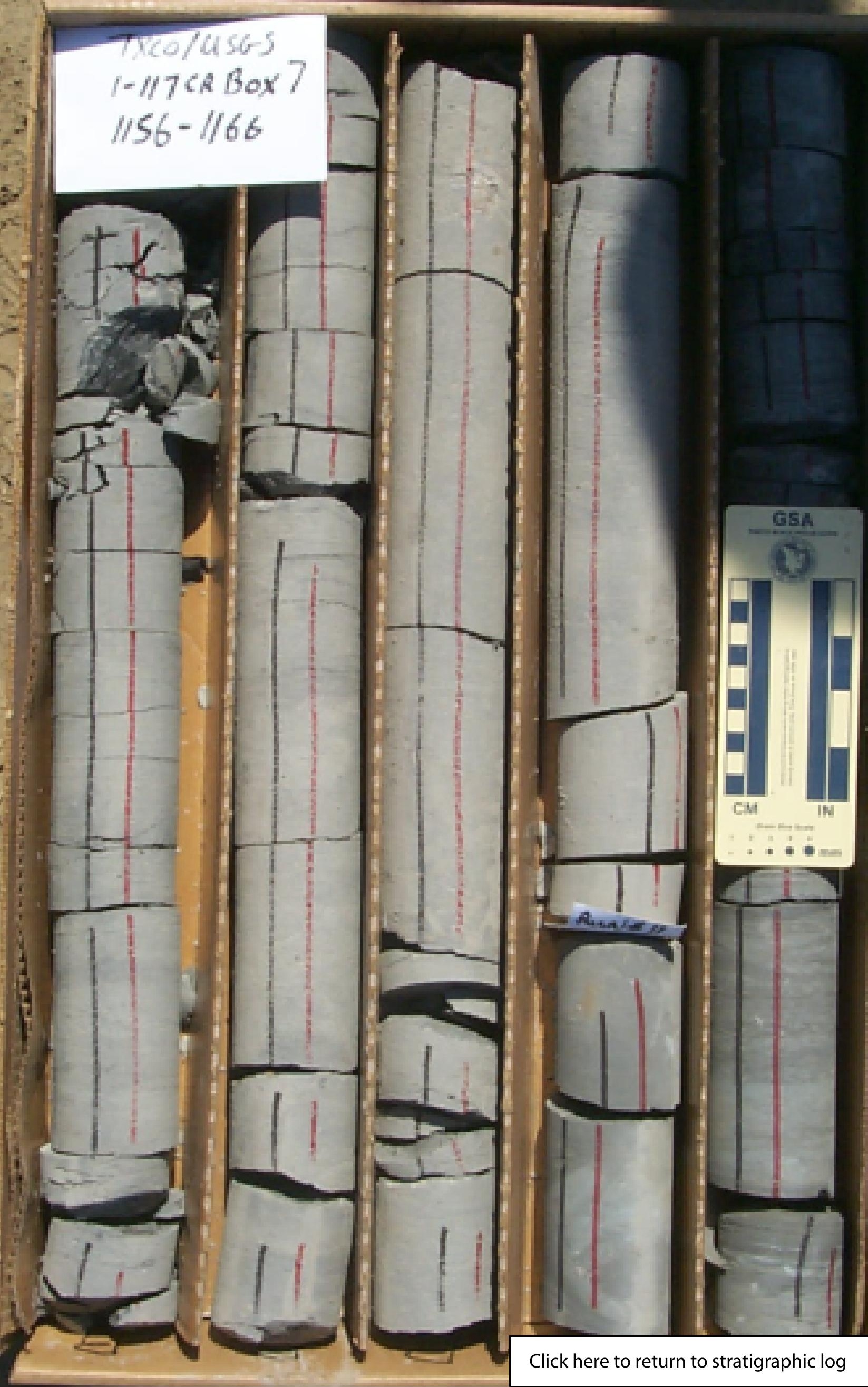




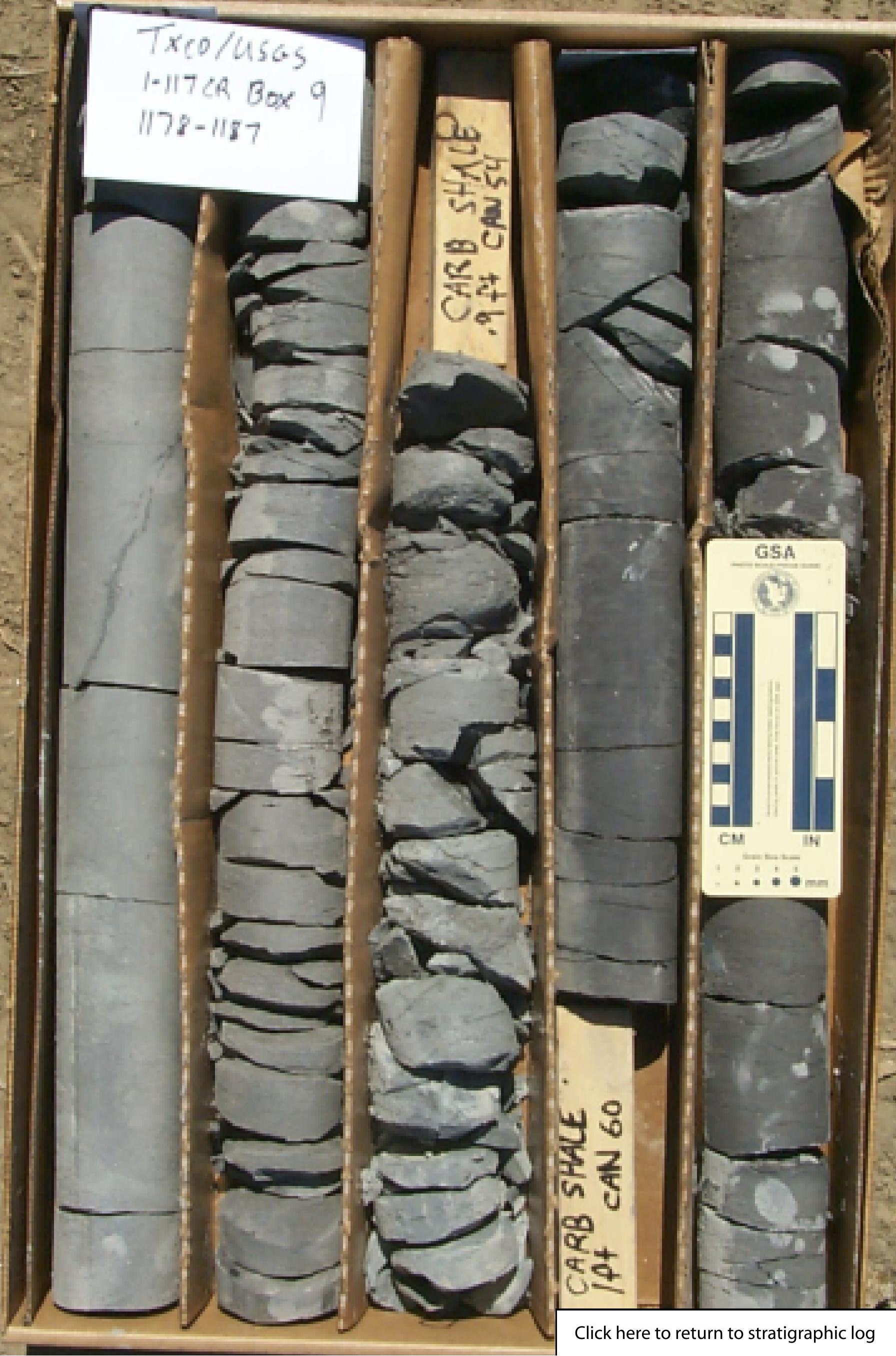




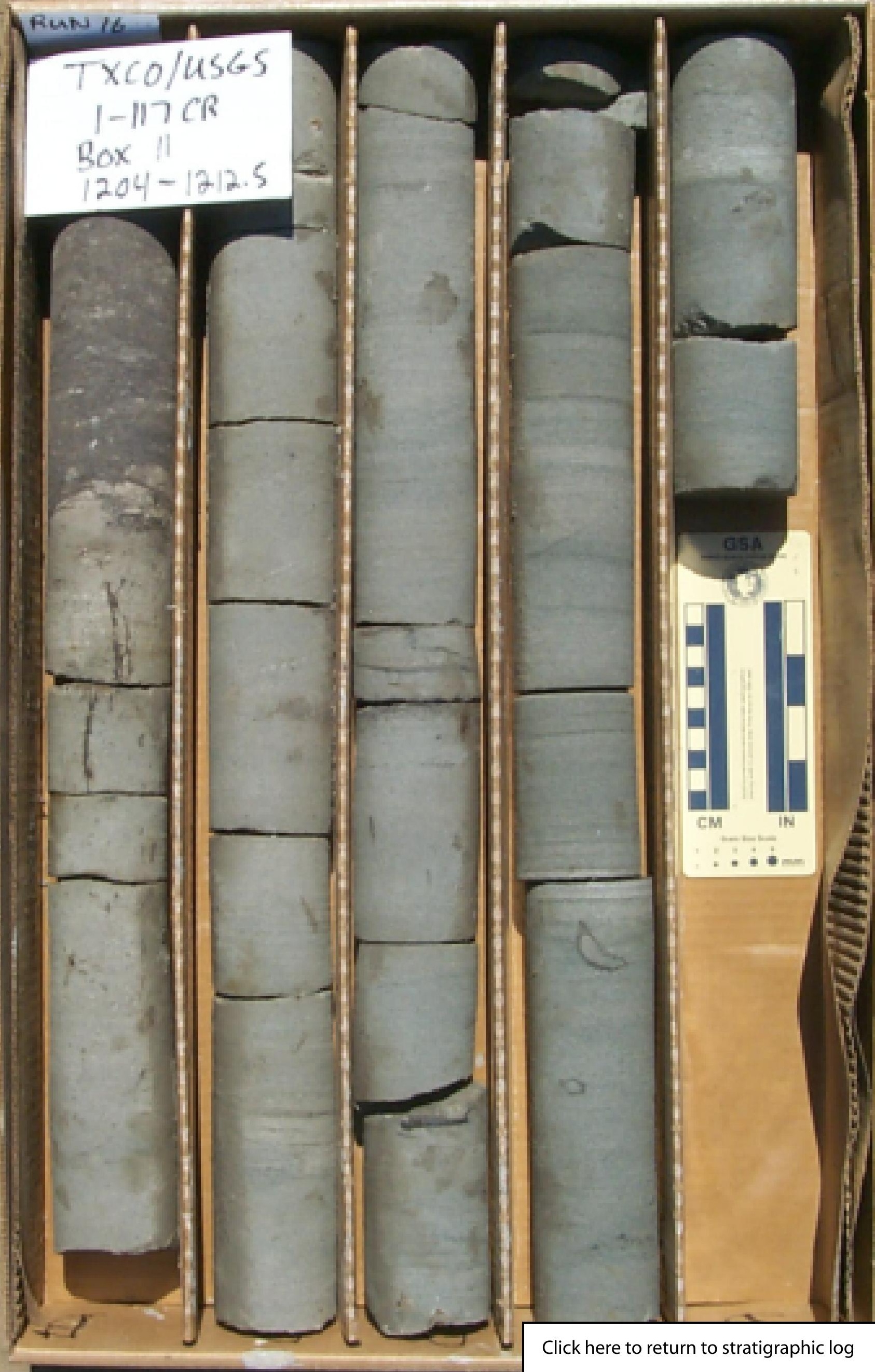


X-ray radiograph

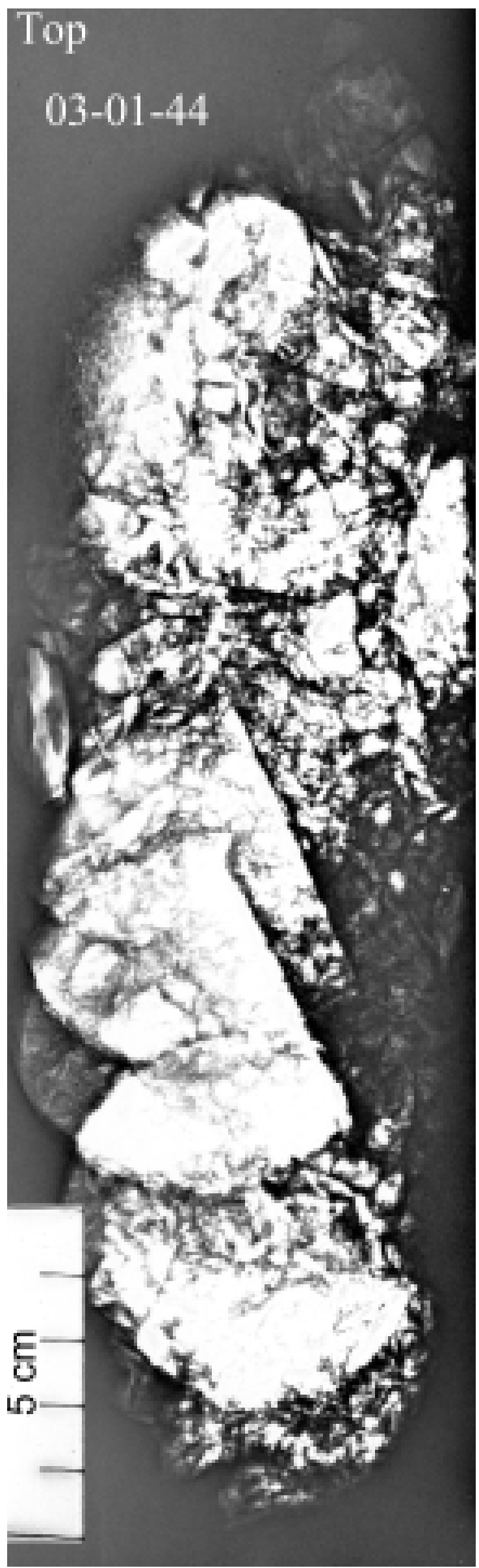

Well: Comanche 1-117CR

Sample:03-01-44

Depth:1101.00 - $1101.45 \mathrm{ft}$

AR Ash: $81.72 \%$

\section{Carbonaceous shale, broken pieces}




\section{X-ray radiograph}

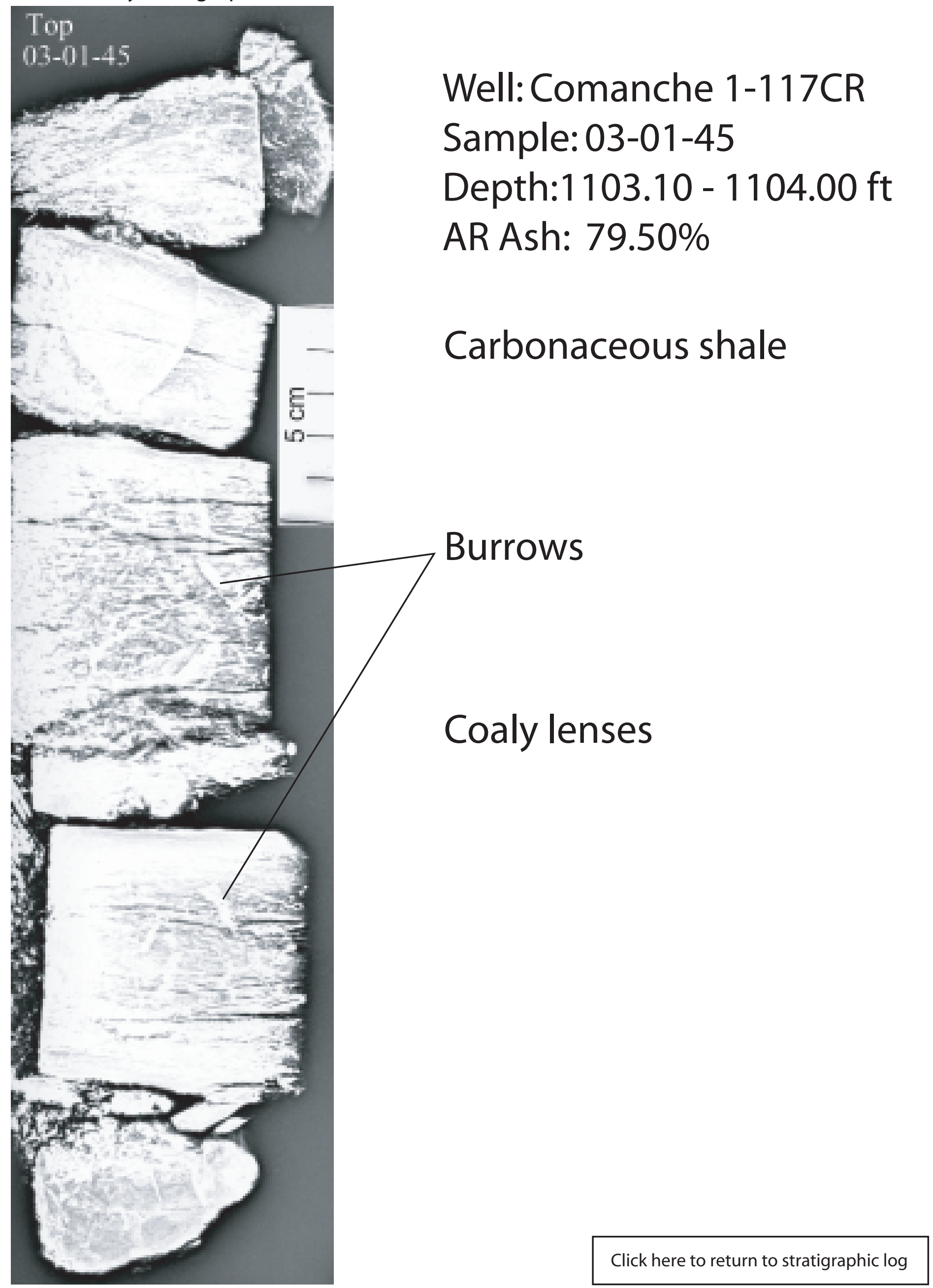


X-ray radiograph

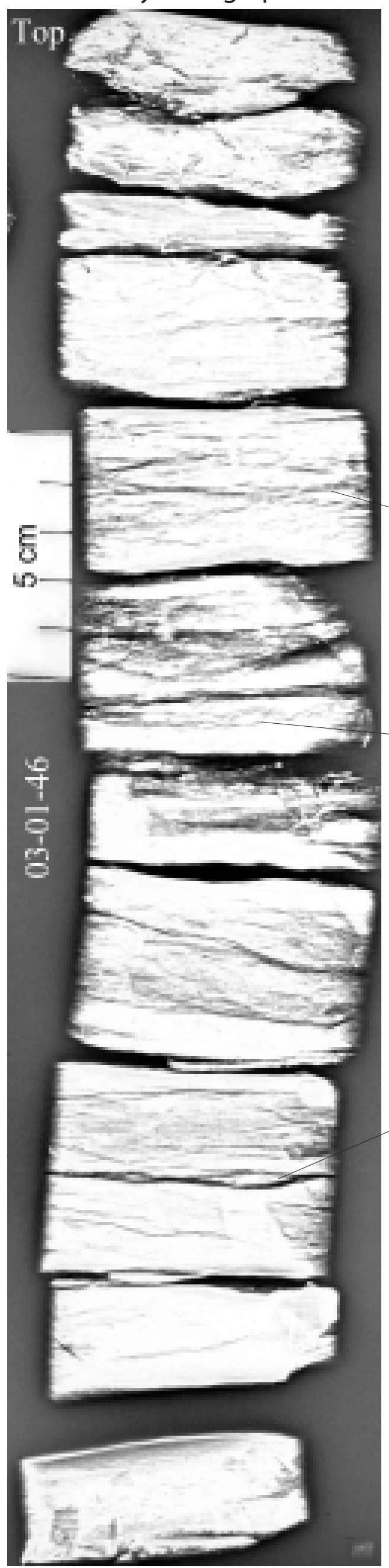

\section{Carbonaceous shale and mudstone}

\section{Coaly stringers}

\section{Burrows}

\section{Ripple laminations?}




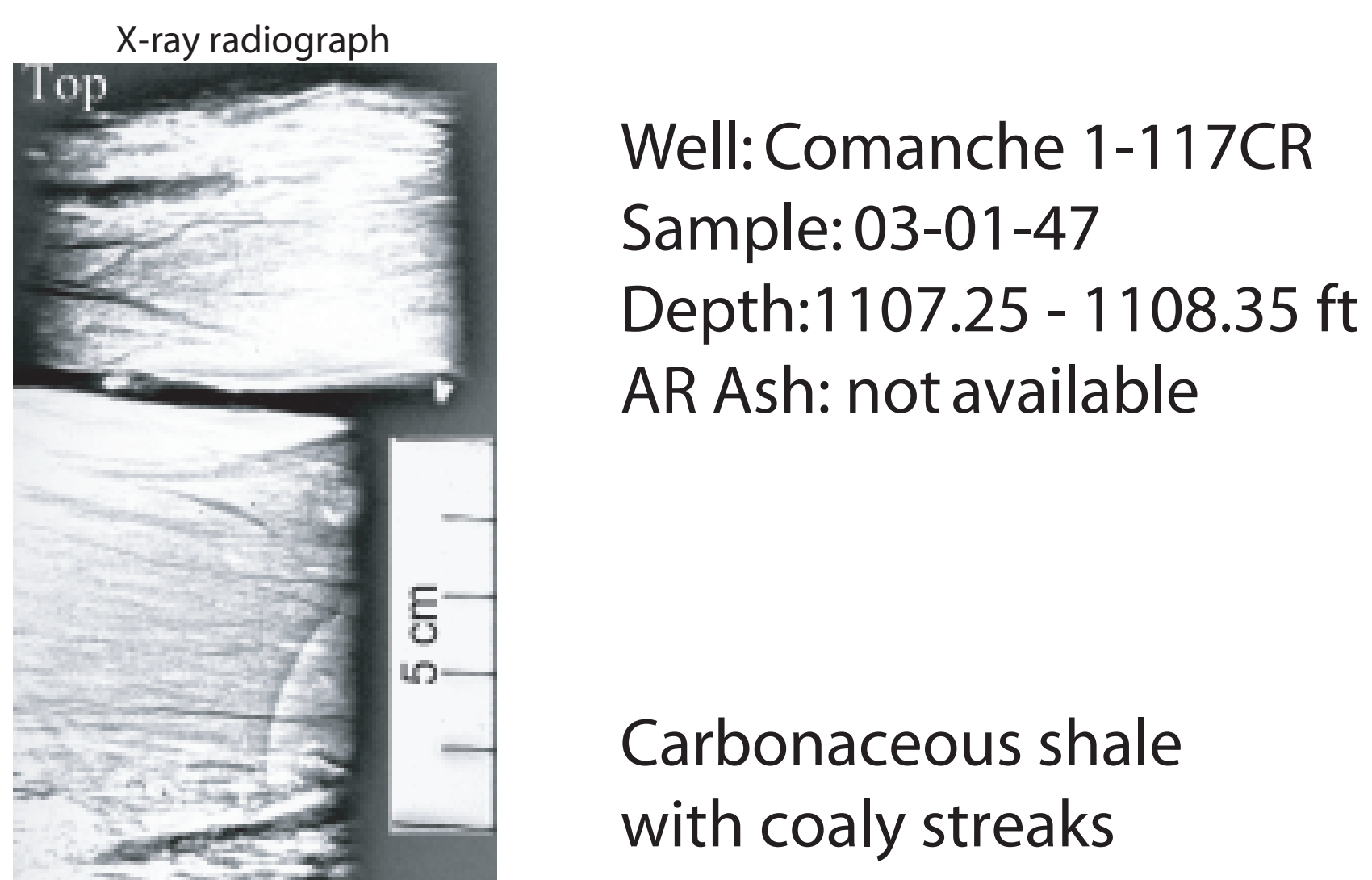


X-ray radiograph

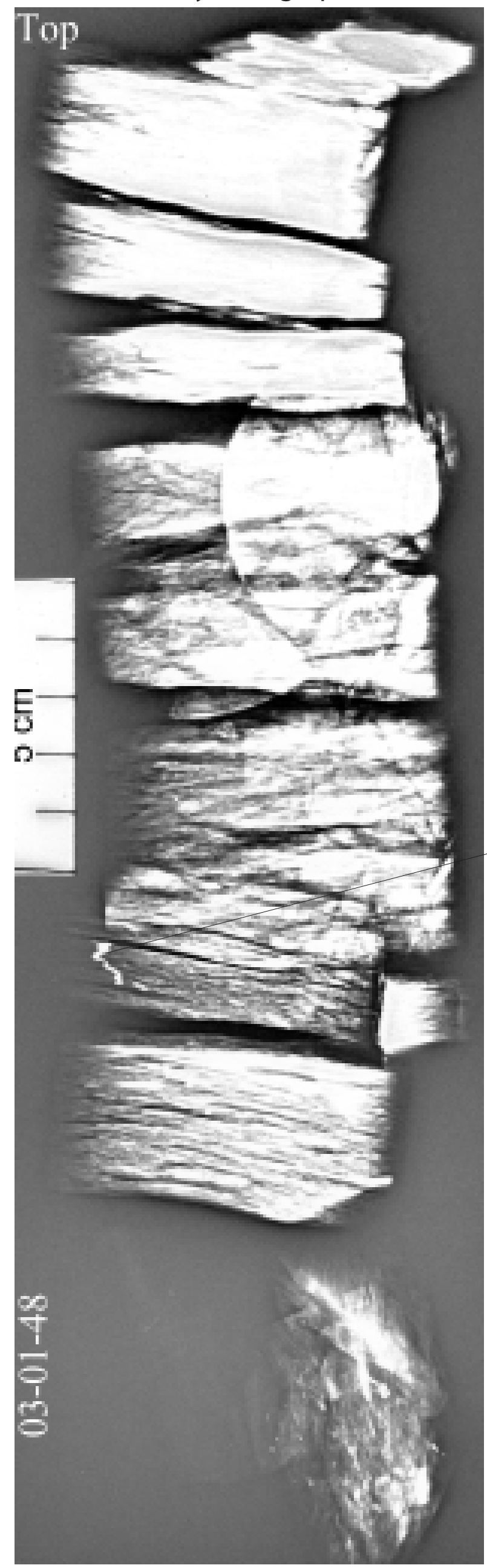

Well: Comanche 1-117CR

Sample: 03-01-48

Depth:1108.35 - $1109.15 \mathrm{ft}$ AR Ash: $60.37 \%$

Carbonaceous shale with coaly streaks

Clay-filled vertical burrow

Becoming more organic-rich towards the base 


\section{X-ray radiograph}

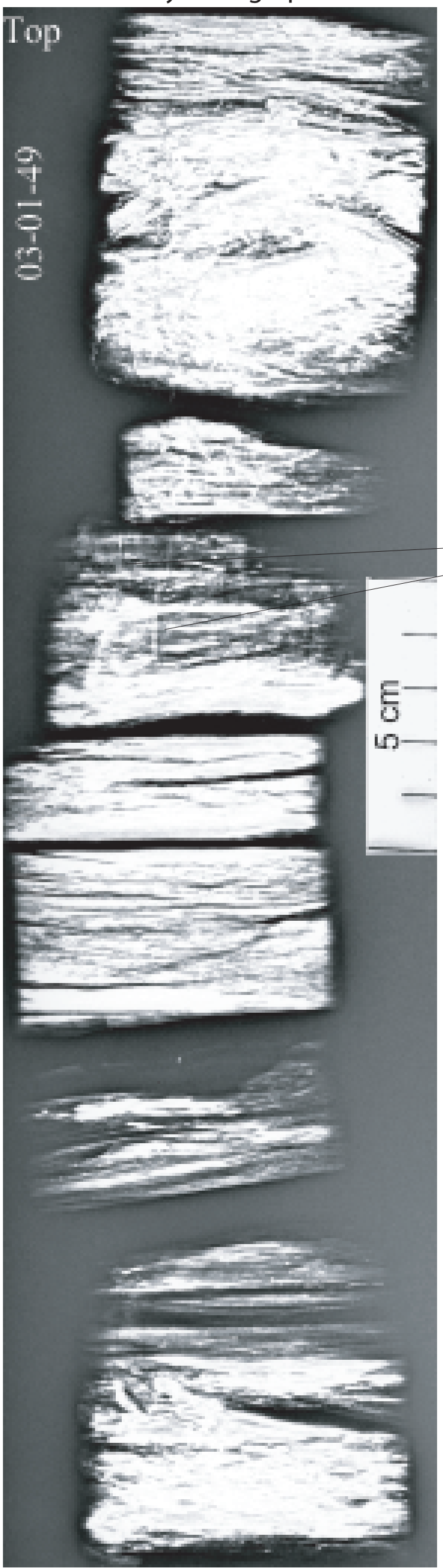

Well: Comanche 1-117CR

Sample: 03-01-49

Depth:1114.70 - $1115.50 \mathrm{ft}$ AR Ash: $45.00 \%$

Cleats, filled with mineralization? with approximately $1 \mathrm{~cm}$ spacing 


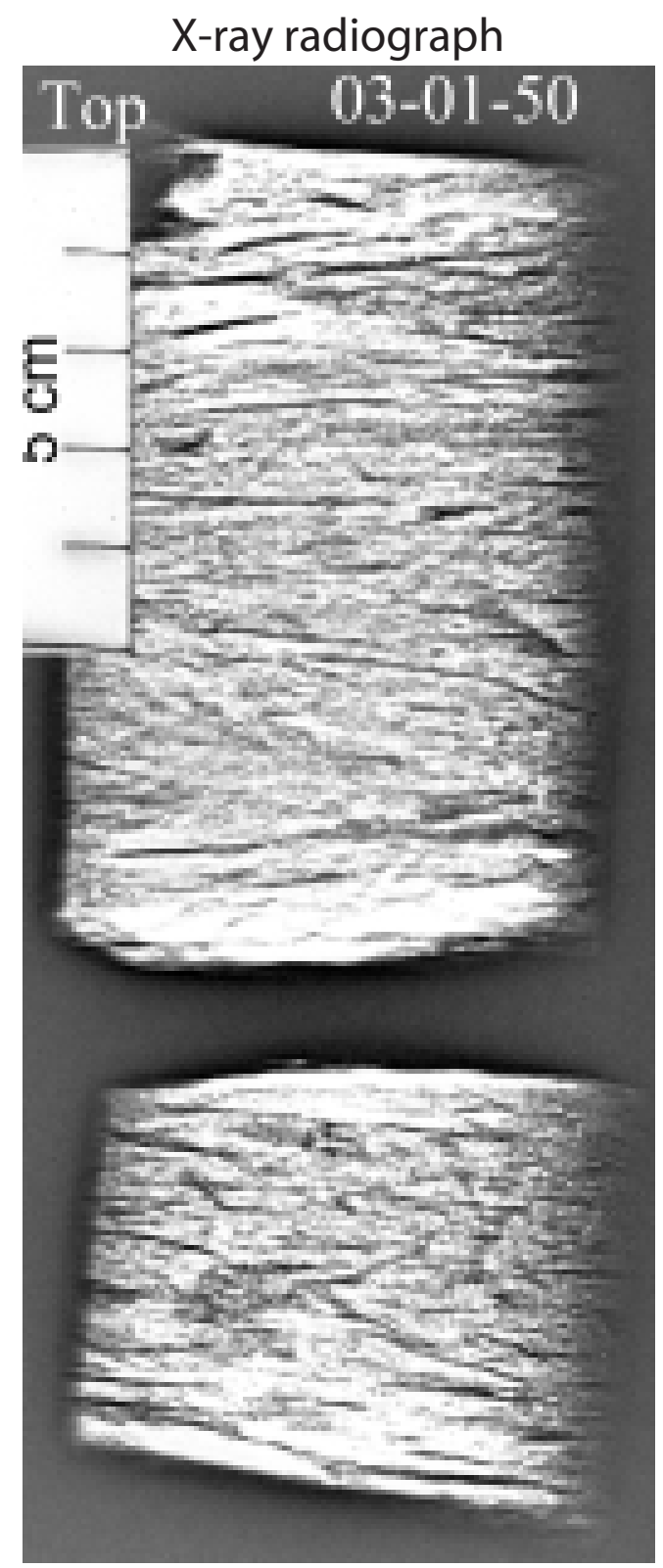

\section{Well: Comanche 1-117CR Sample: 03-01-50 Depth:1152.60 - $1153.00 \mathrm{ft}$ AR Ash: $62.91 \%$}

\section{Carbonaceous shale with coaly lenses}


X-ray radiograph

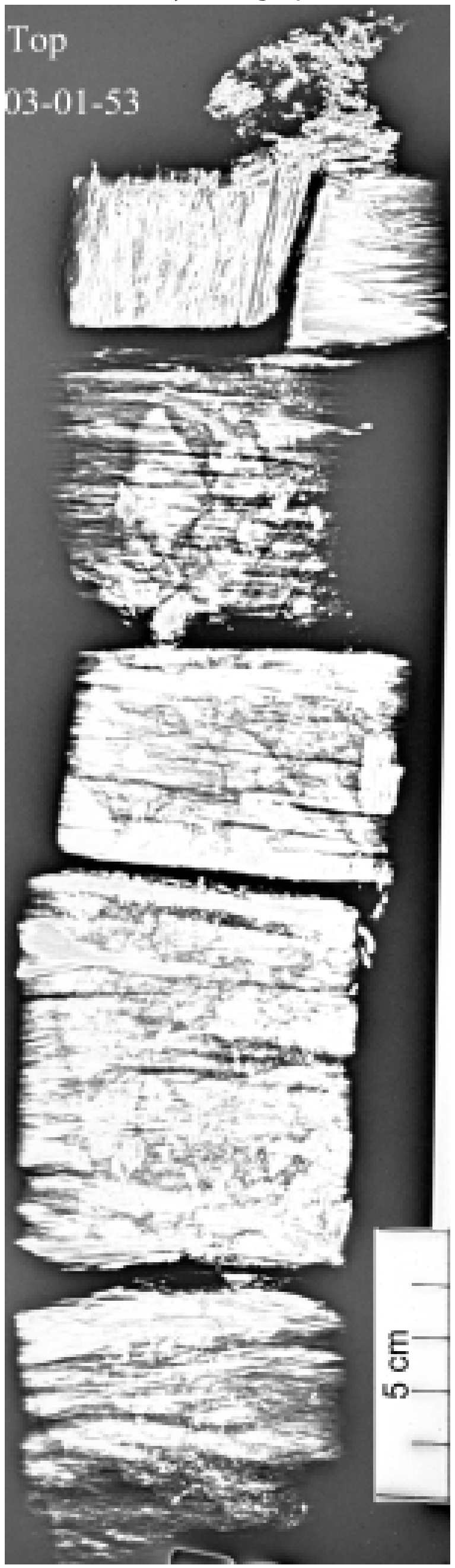

Well: Comanche 1-117CR

Sample: 03-01-53

Depth:1166.10 - $1167.40 \mathrm{ft}$

AR Ash: $38.30 \%$

Coal, shaley, with

burrows and shale lenses

\section{Zone with high ash content}




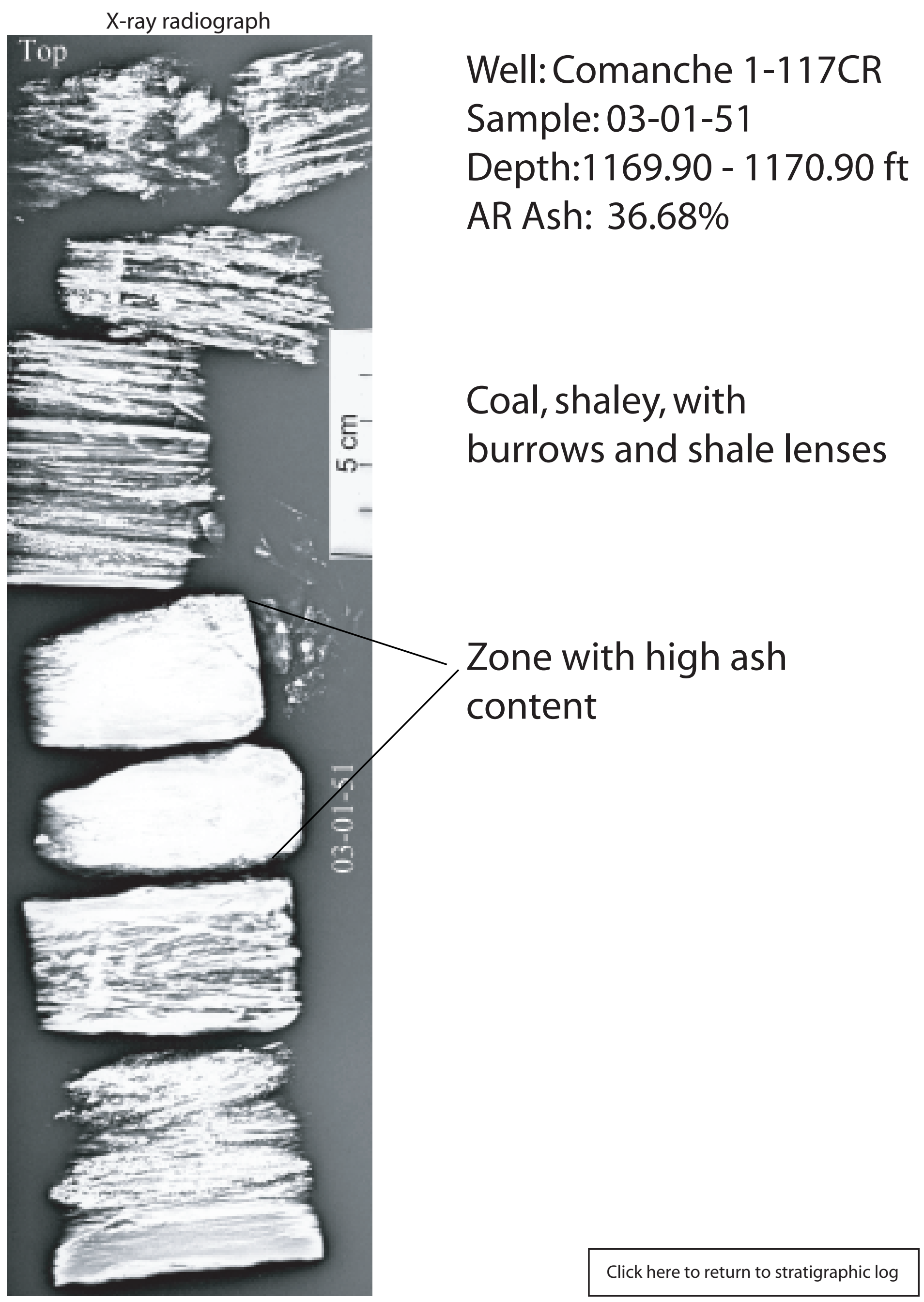




\section{X-ray radiograph}

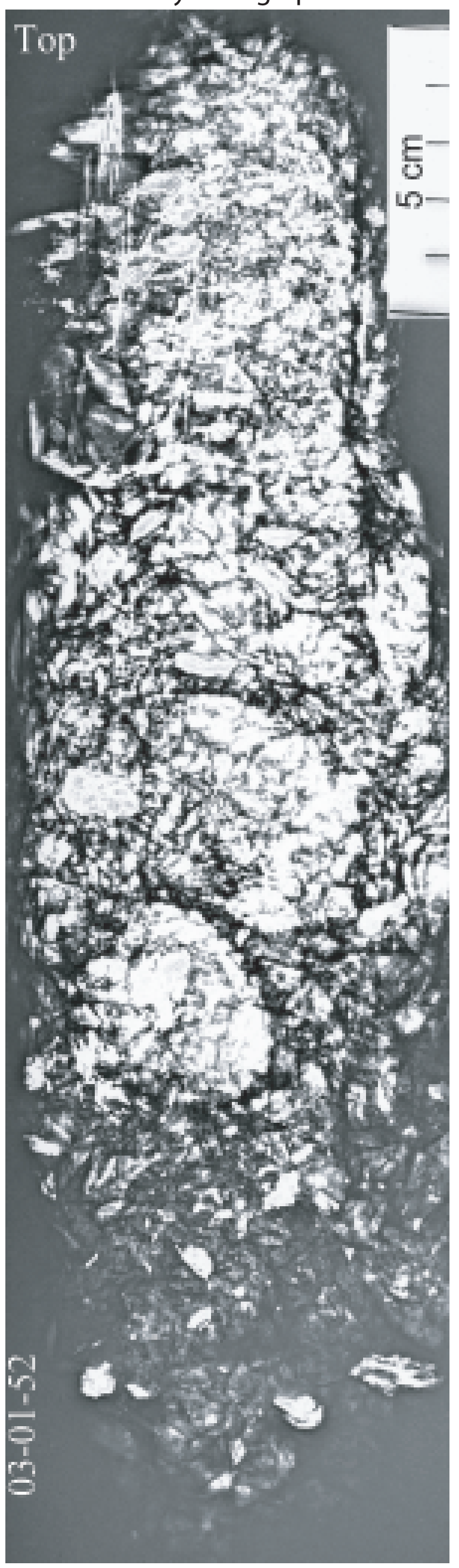

Well: Comanche 1-117CR

Sample: 03-01-52

Depth:1170.90 - $1171.50 \mathrm{ft}$

AR Ash: $63.81 \%$

\section{Carbonaceous shale, broken pieces}


X-ray radiograph

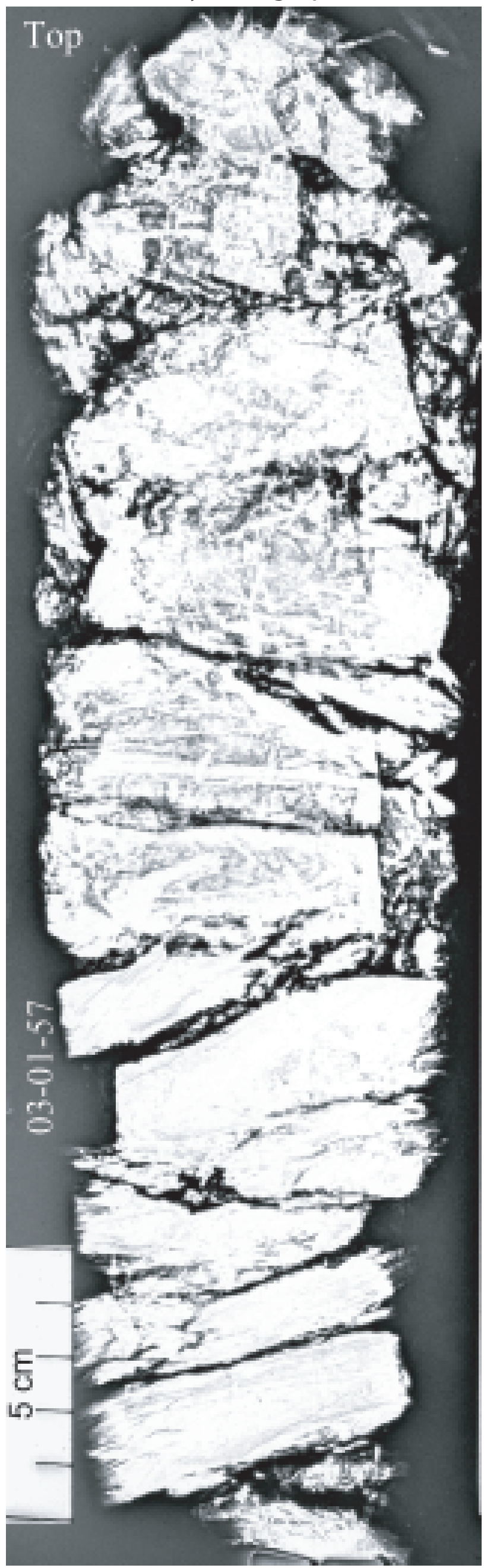

\section{Carbonaceous shale, broken pieces}




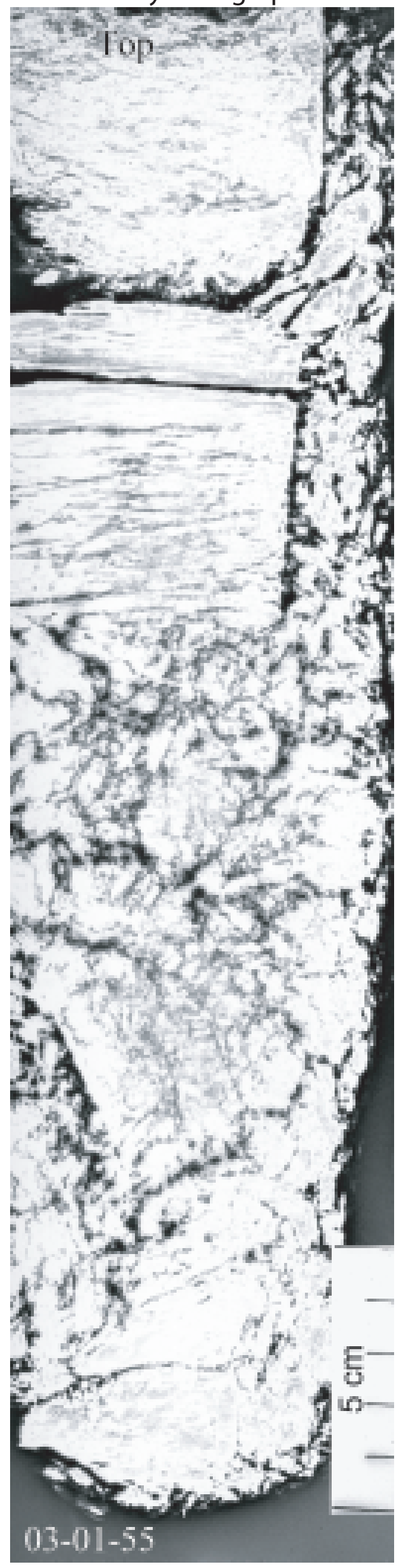

\section{Well: Comanche 1-117CR Sample: 03-01-55 \\ Depth:1174.70 - $1175.70 \mathrm{ft}$ AR Ash: $71.61 \%$}

\section{Carbonaceous shale with burrows and coaly lenses}




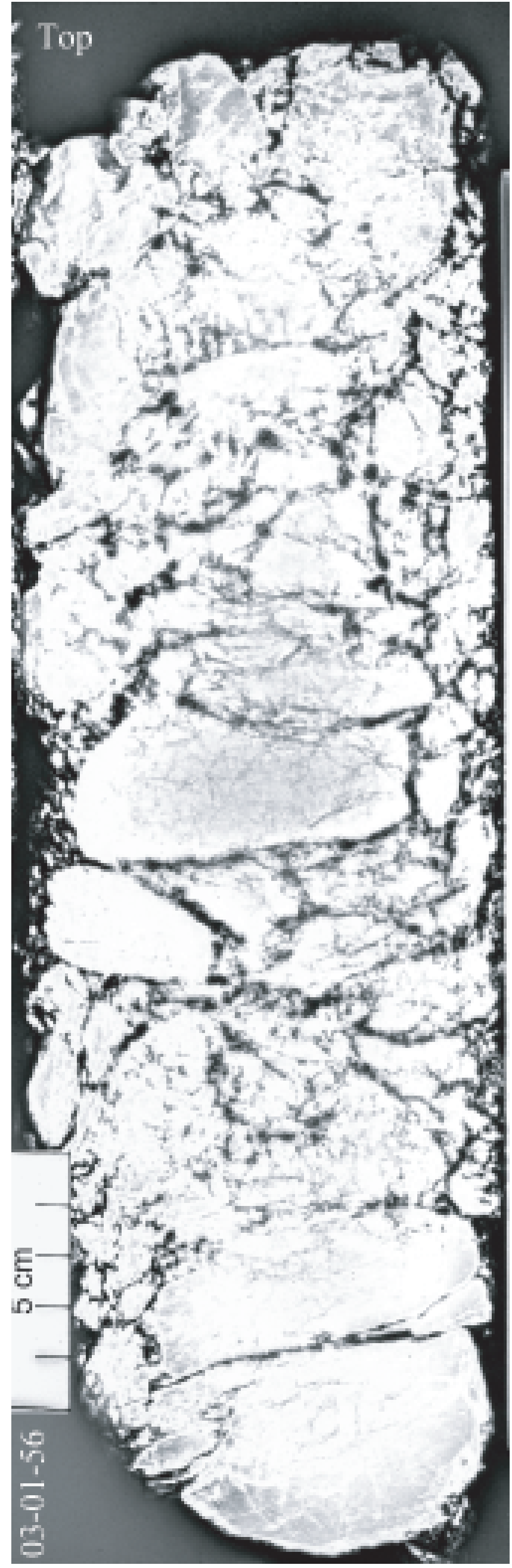

\section{Well: Comanche 1-117CR Sample:03-01-56 Depth:1175.70 - $1176.80 \mathrm{ft}$ AR Ash: $82.69 \%$}

\section{Carbonaceous shale, broken pieces}


X-ray radiograph

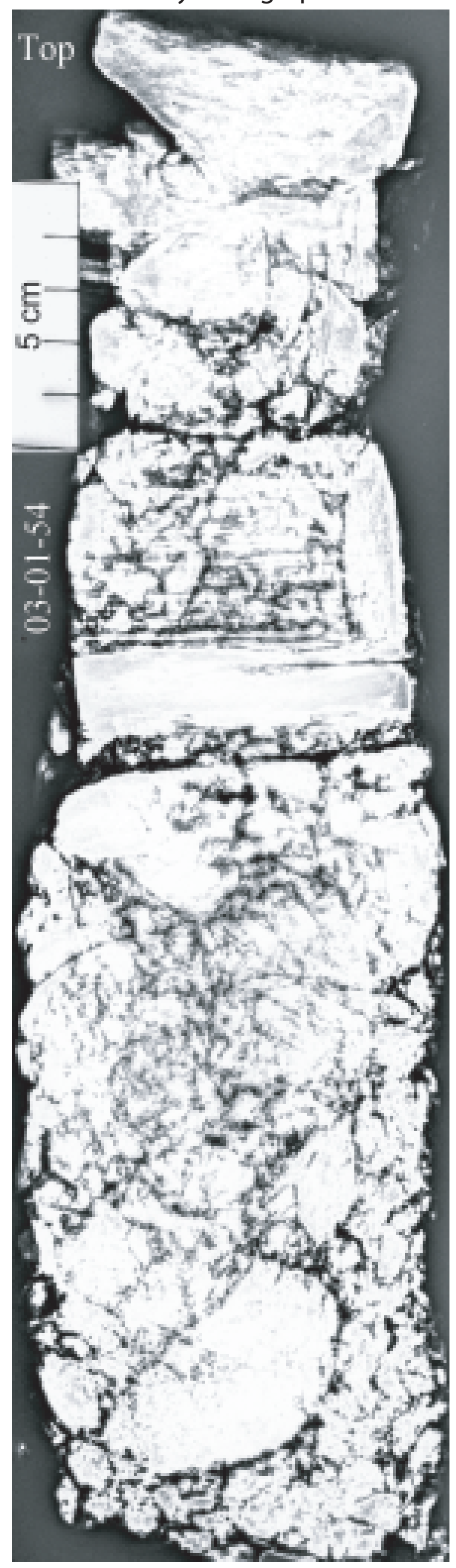

Carbonaceous shale, broken pieces 


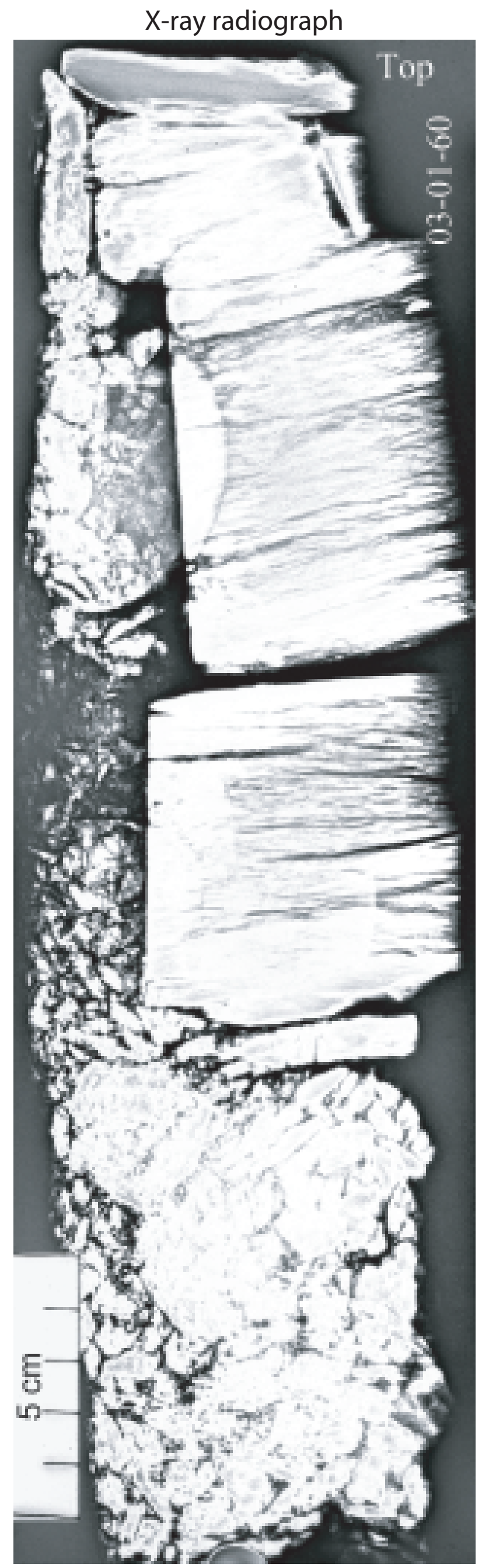

\section{Carbonaceous shale with coaly lenses}

\section{Carbonaceous shale, broken pieces}




\section{X-ray radiograph}

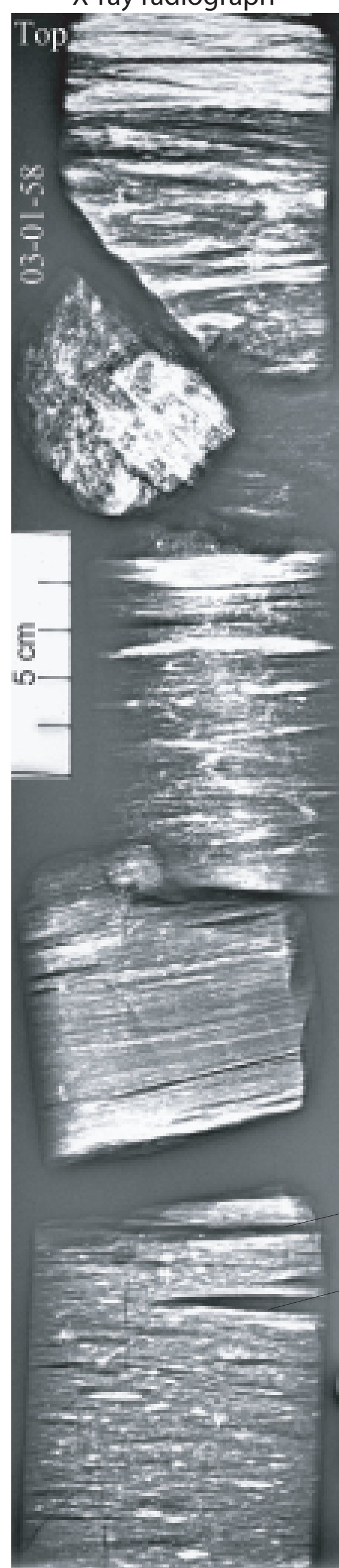

Well: Comanche 1-117CR

Sample: 03-01-58

Depth:1189.80 - $1190.80 \mathrm{ft}$

AR Ash: $16.37 \%$

Coal with shale lenses

Coal with horizontal and vertical burrows

Coal, laminated with horizontal burrows

Woody lenses compressed root? cross-sections

Coal with horizontal burrows and vertical cleat development 
X-ray radiograph

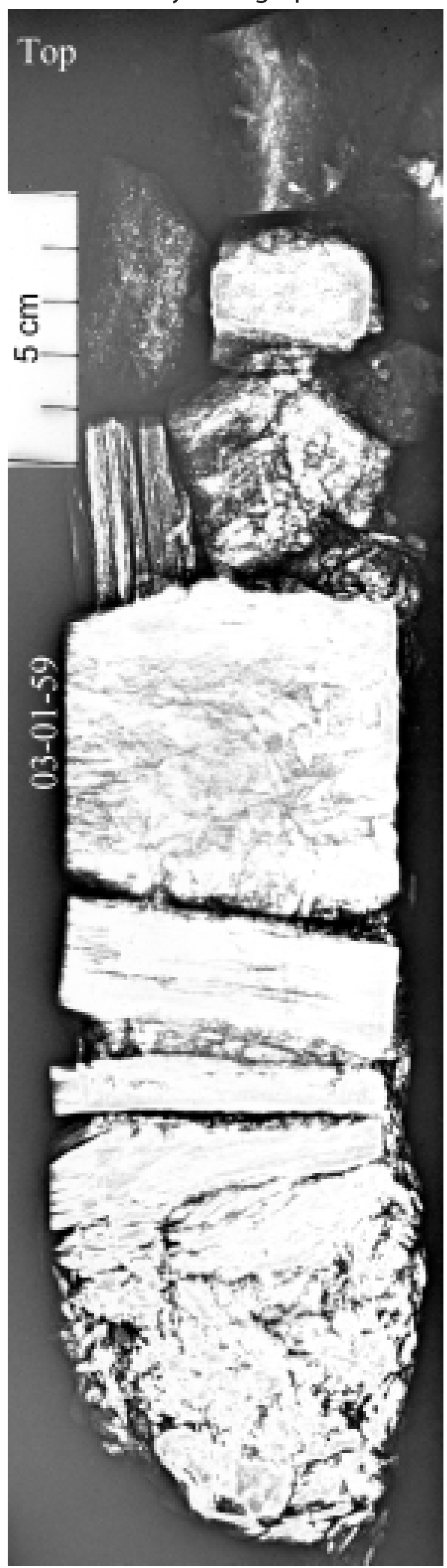

\section{Coal with shale lenses and burrows}

Carbonaceoous shale with coaly lenses 



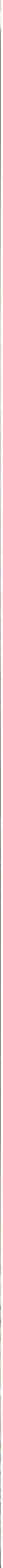


TXCO 1-613CR

1410.00-1419.15'

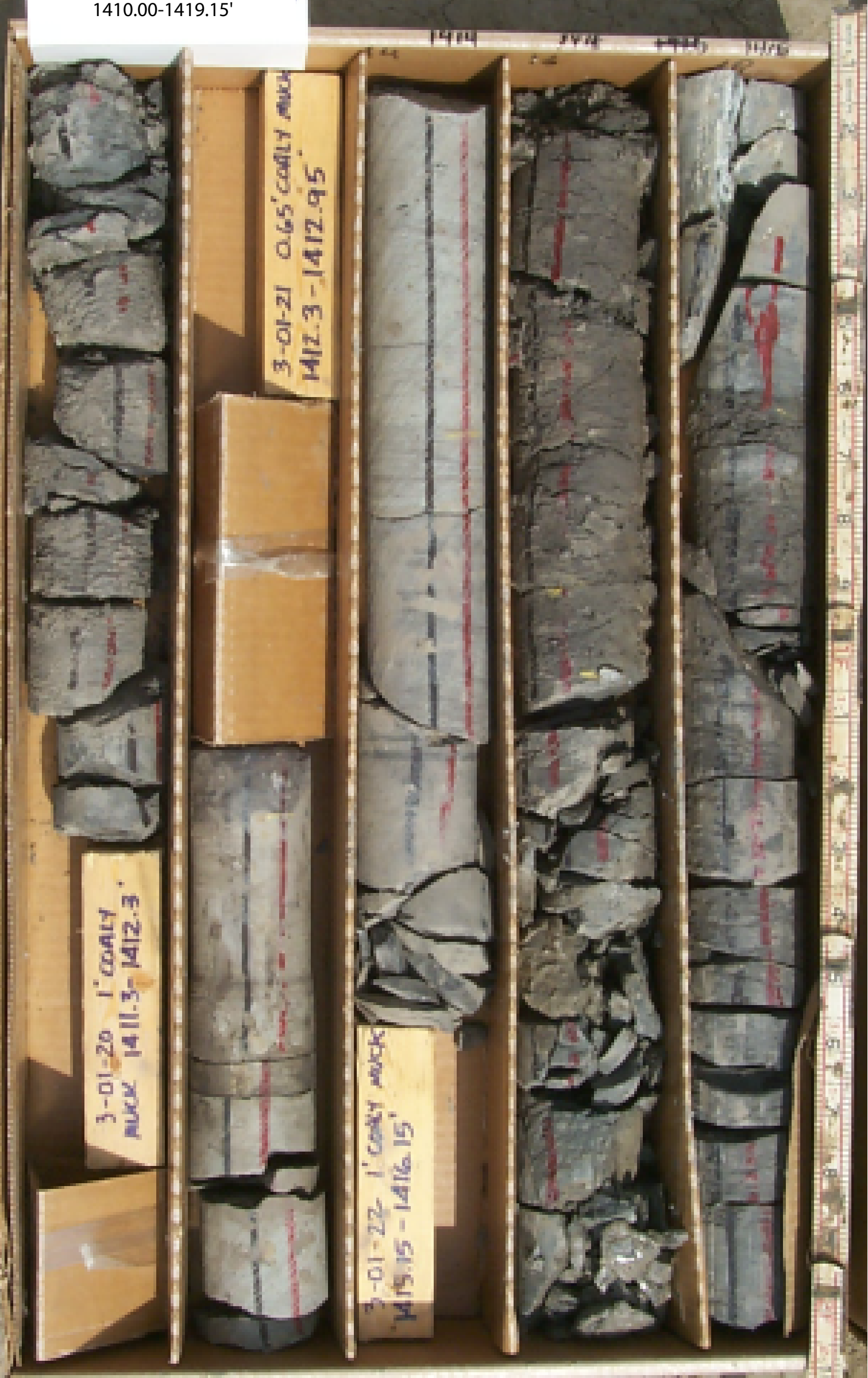




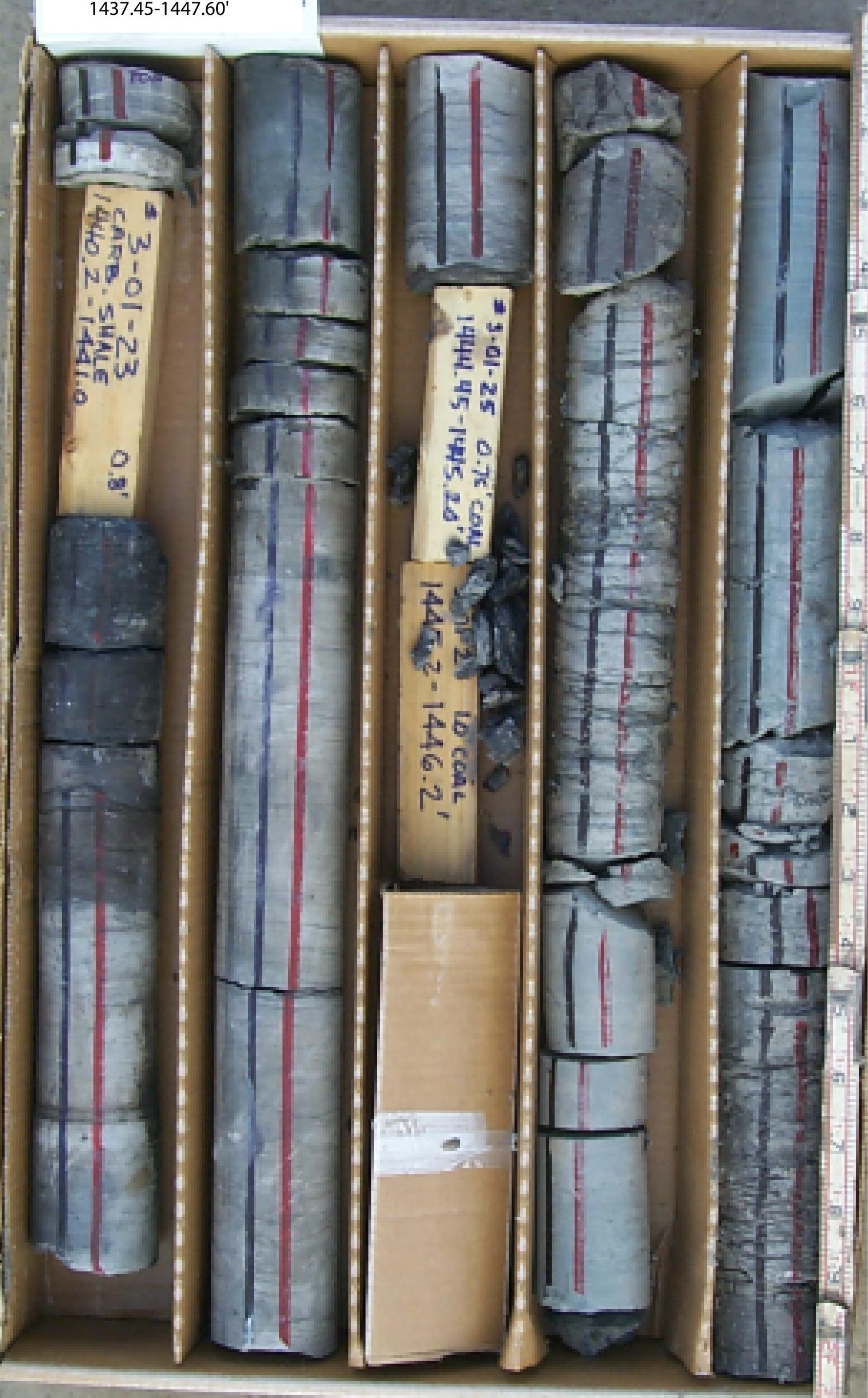




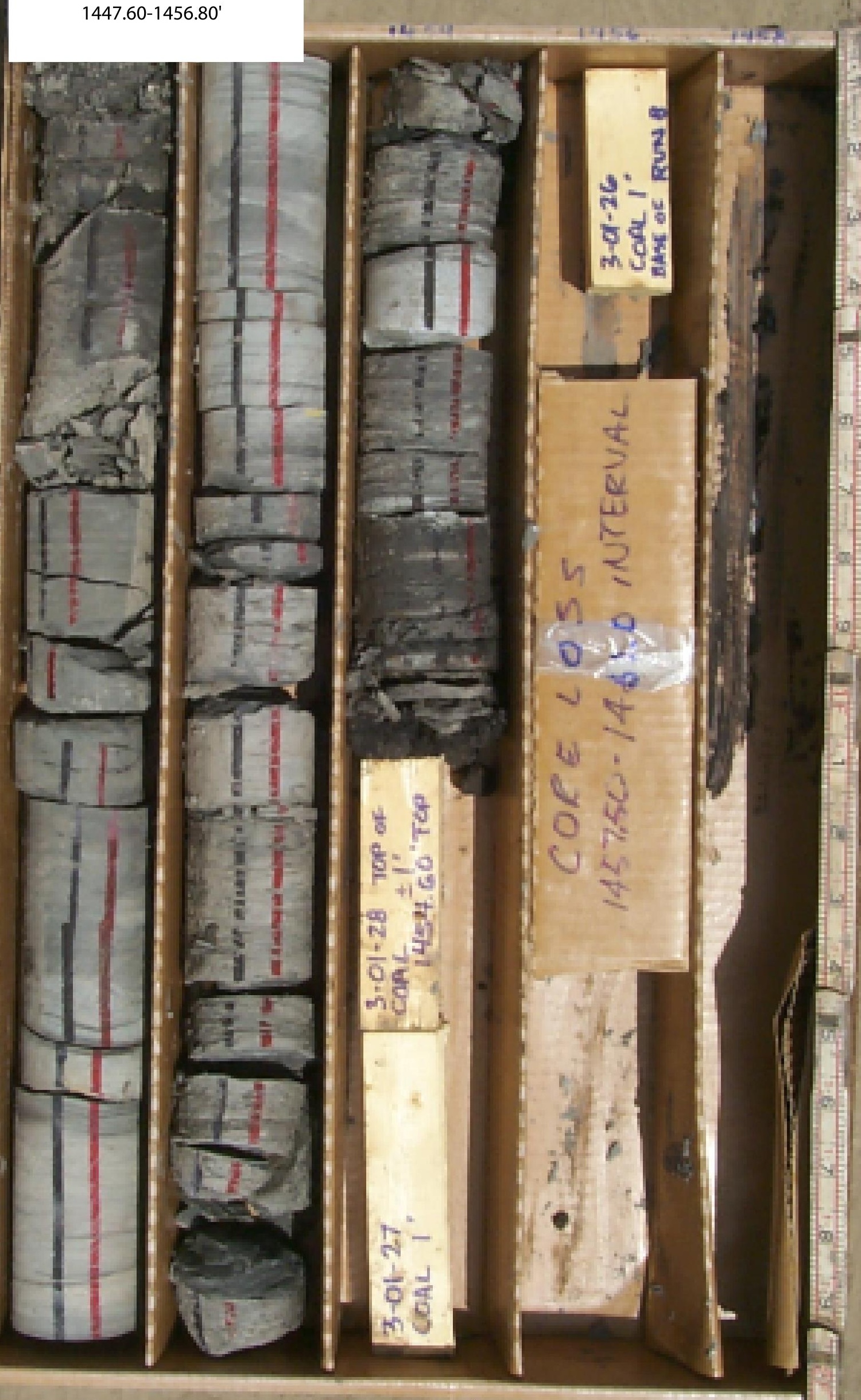




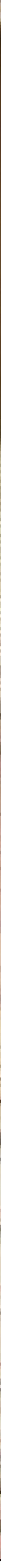


$4 x^{2}-5$
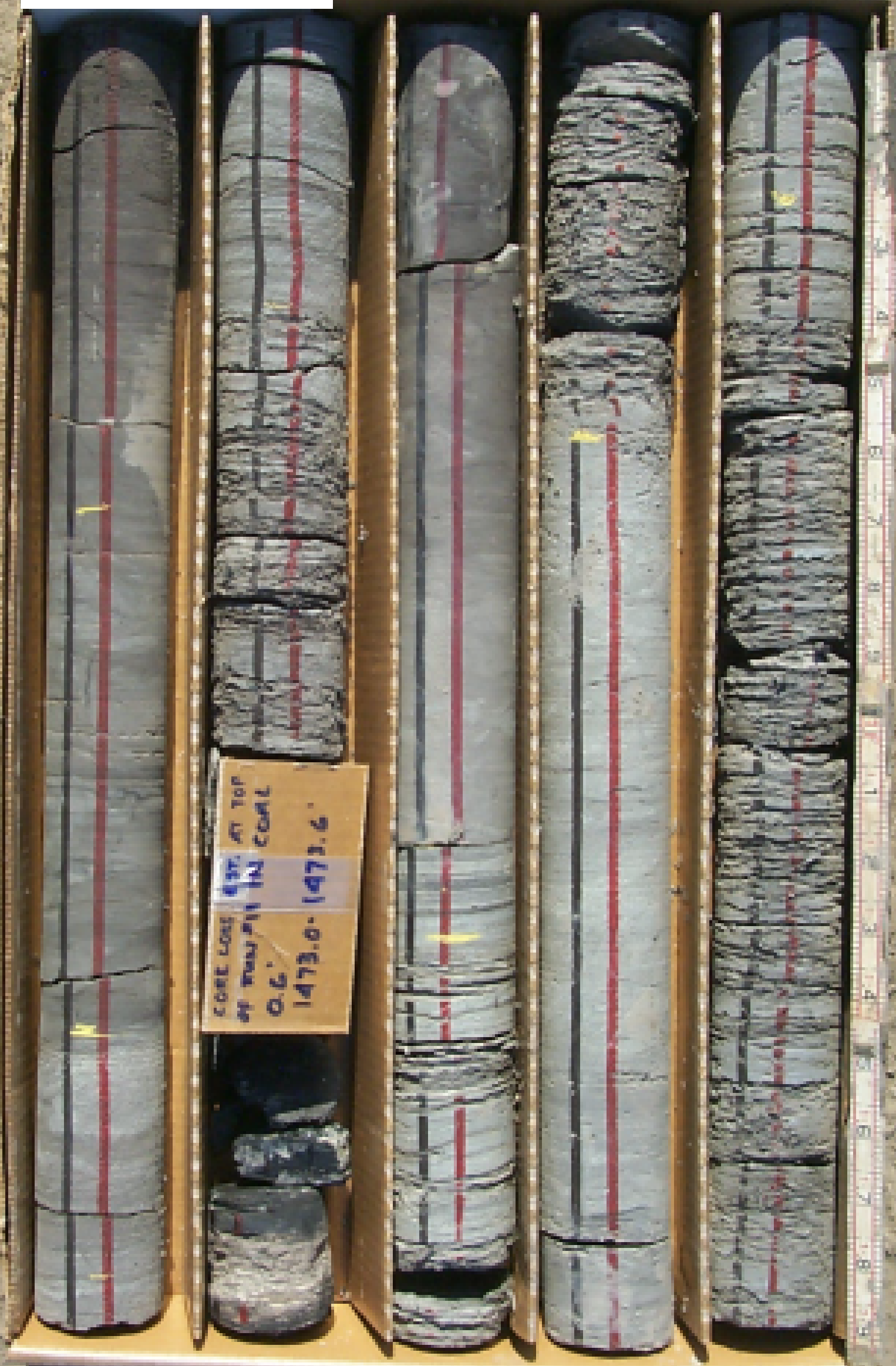


\section{$\frac{1}{1}$}
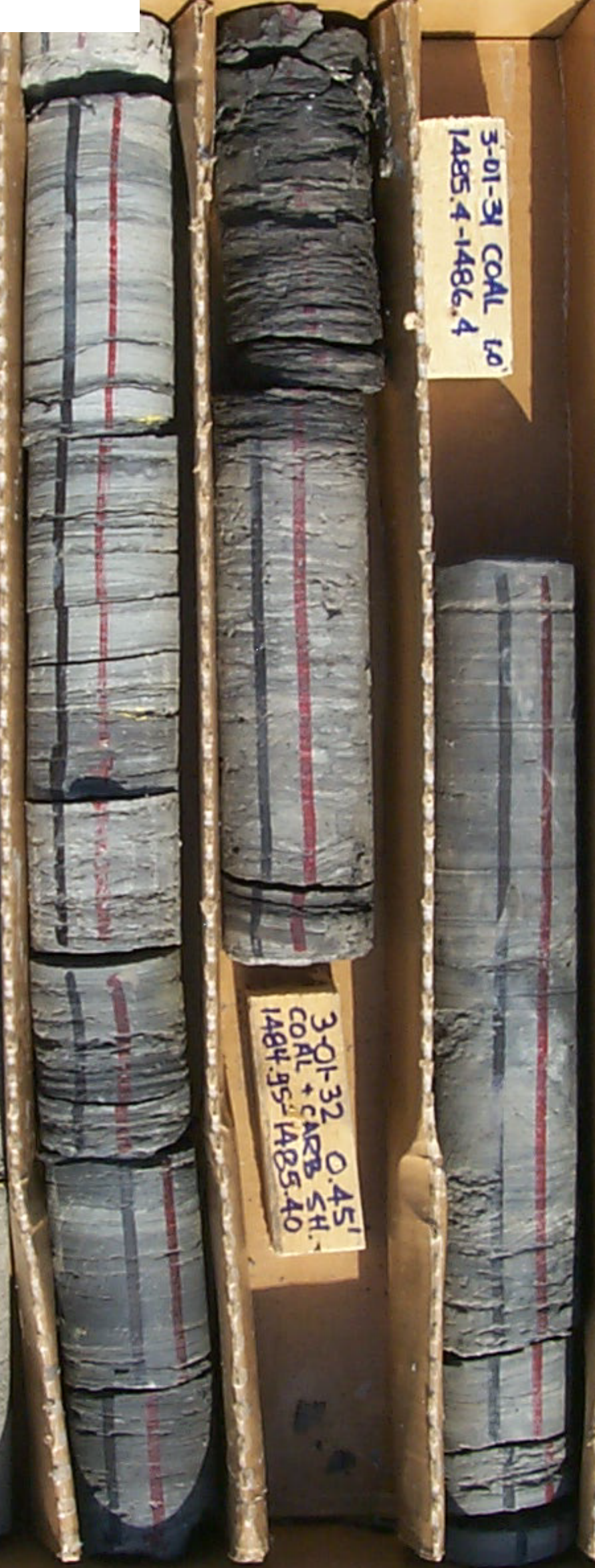

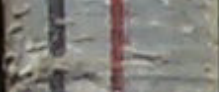

7)
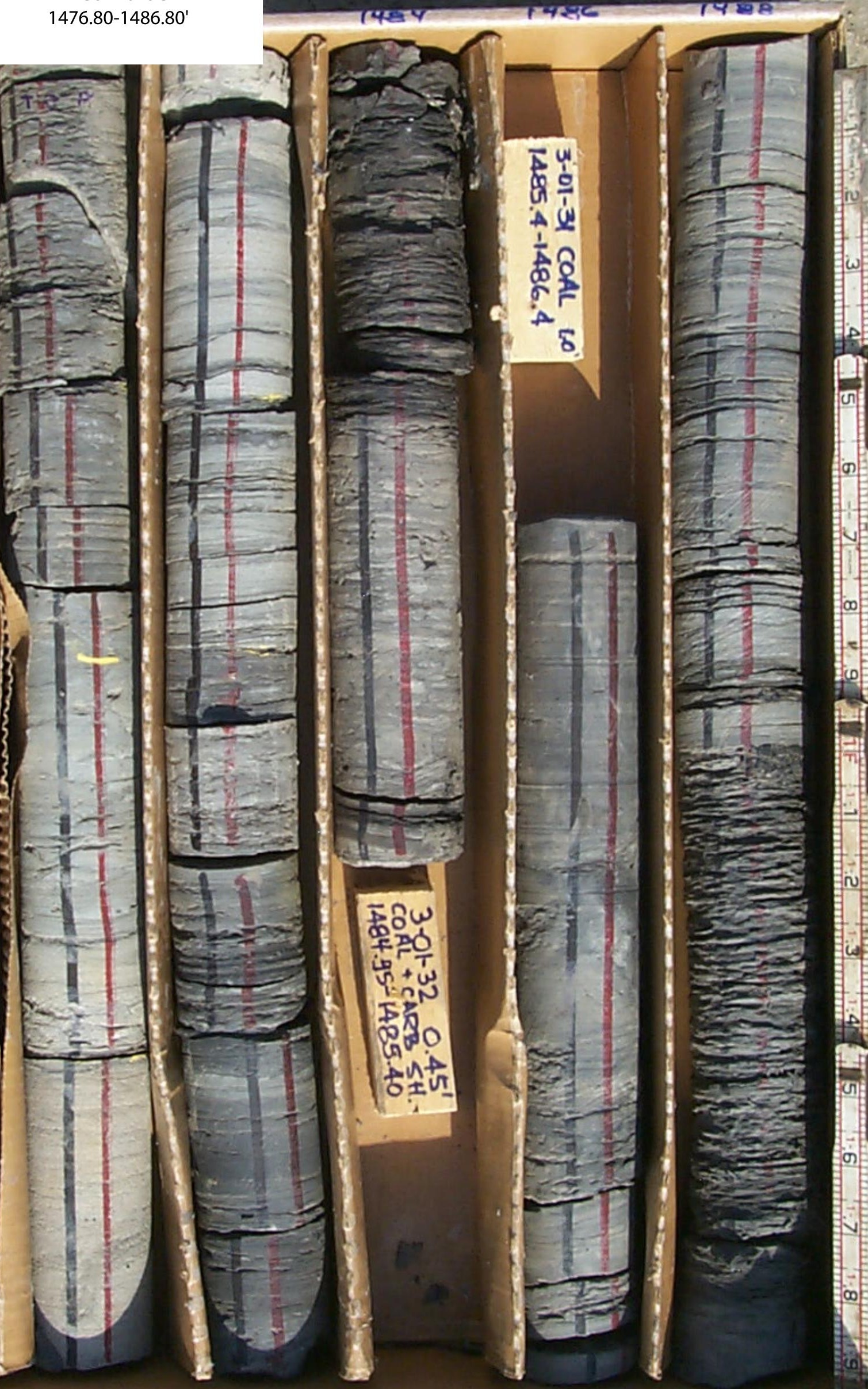

$-9=$

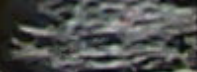

$x-\frac{1}{5}$

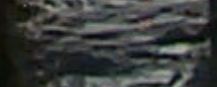

$x \rightarrow 3$

?

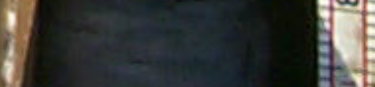




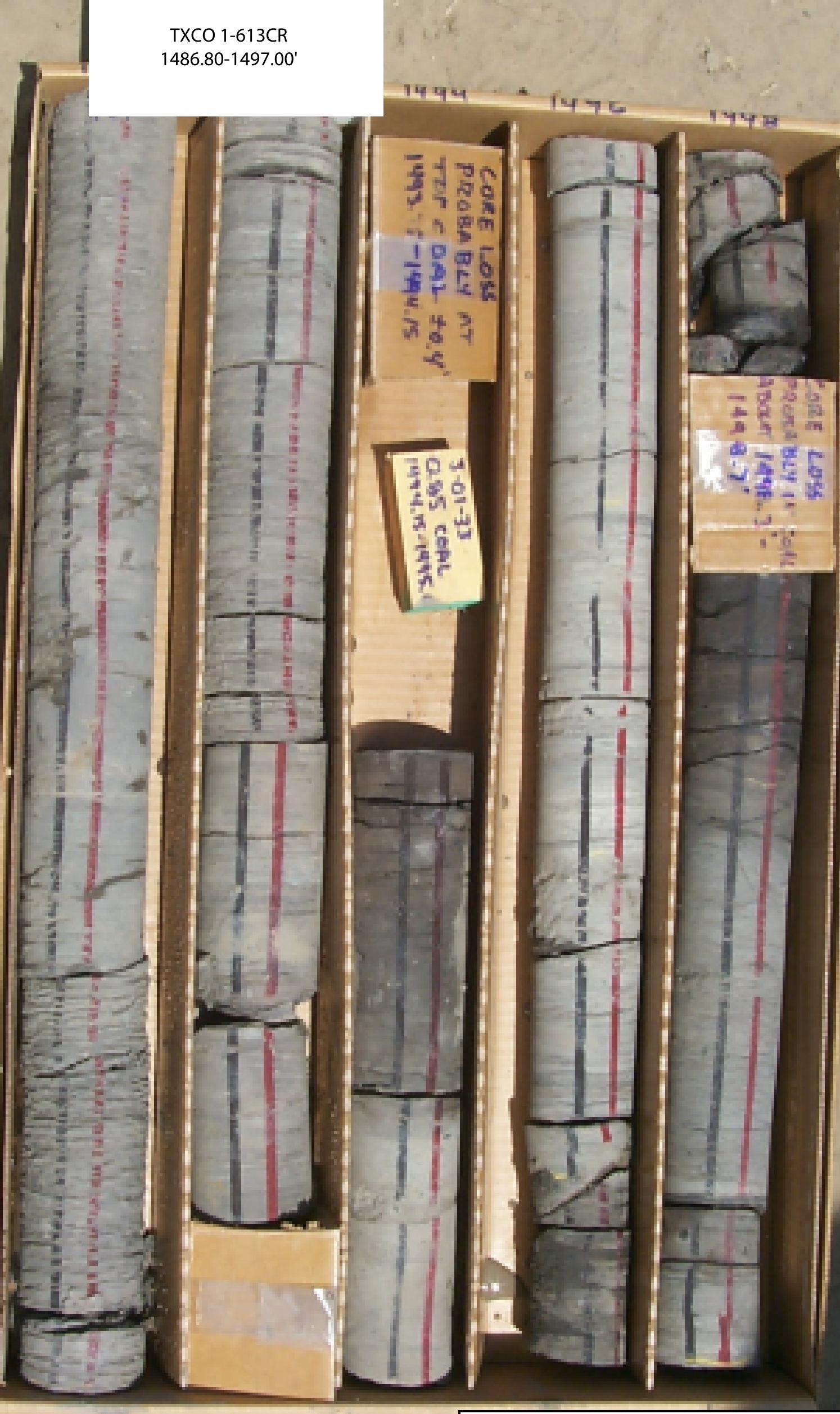

TXCO 1-613CR

144 


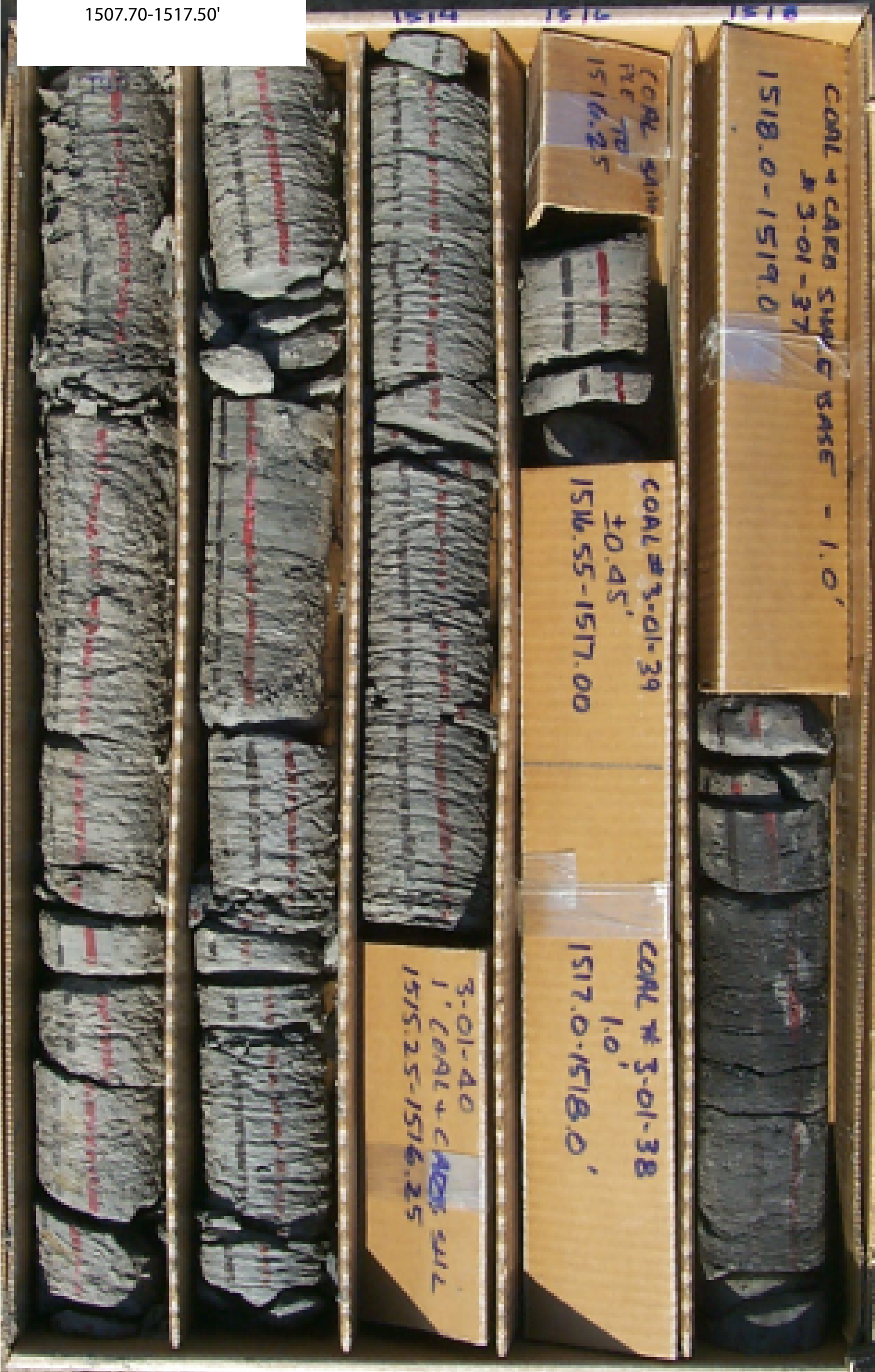




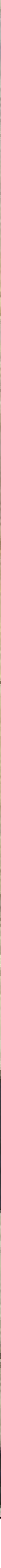


X-ray radiograph

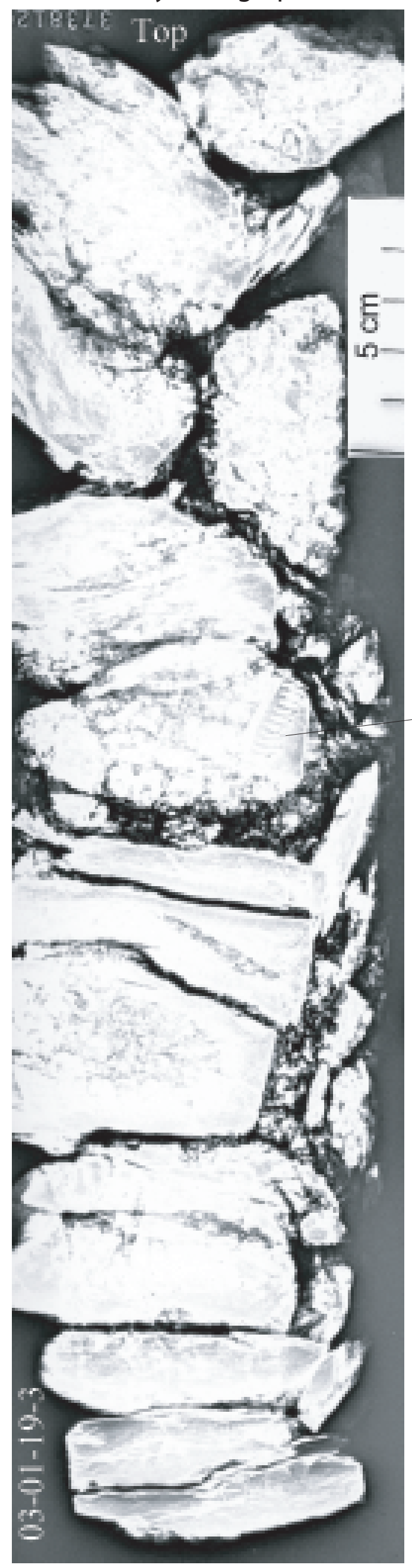

\section{Well: Comanche 1-613CR \\ Sample: 03-01-19 \\ Depth:1402.90 - $1403.90 \mathrm{ft}$ \\ AR Ash: not available}

\section{Carbonaceous shale with coaly lenses}

\section{Transistor (not part of core)}


X-ray radiograph

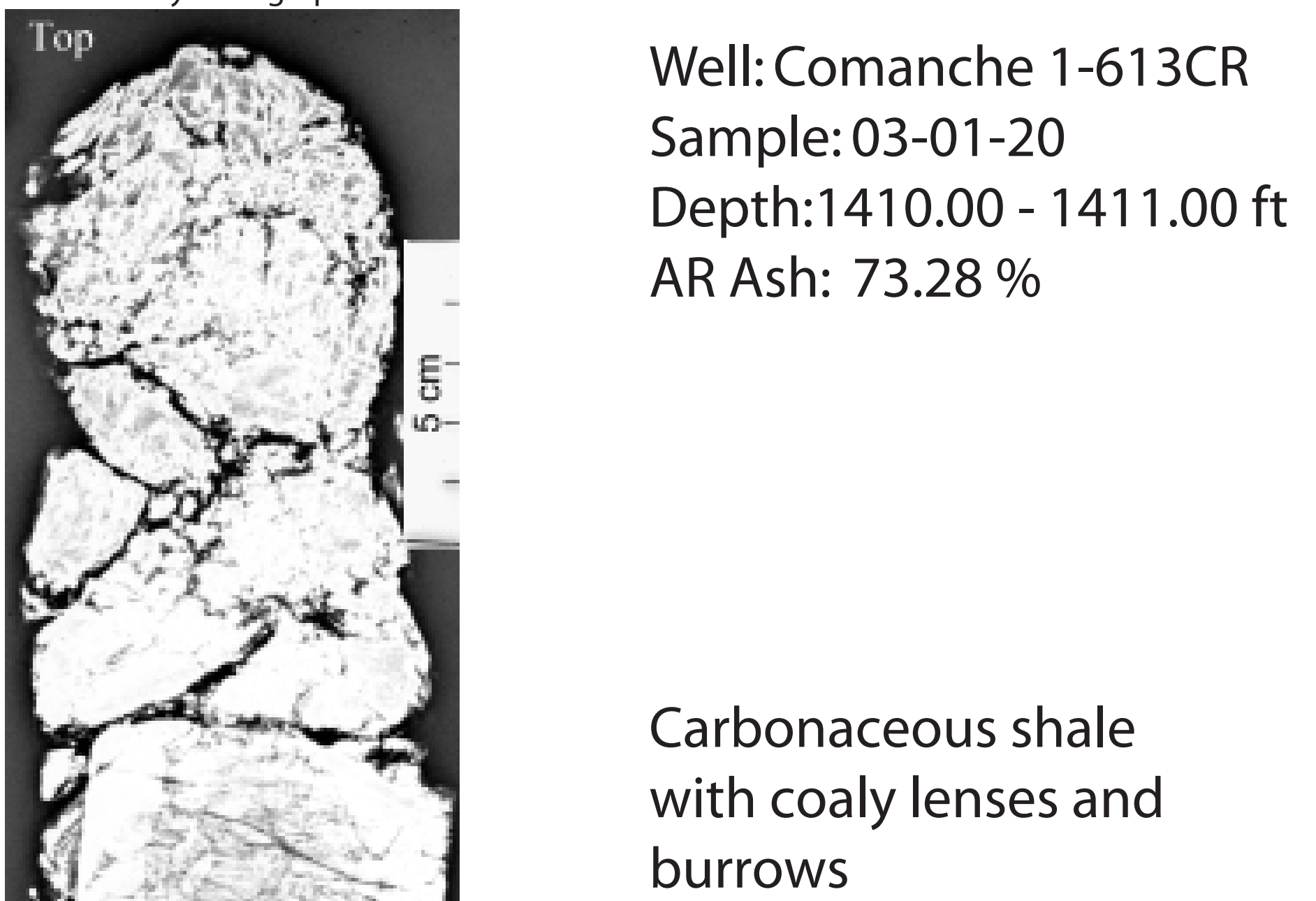


X-ray radiograph

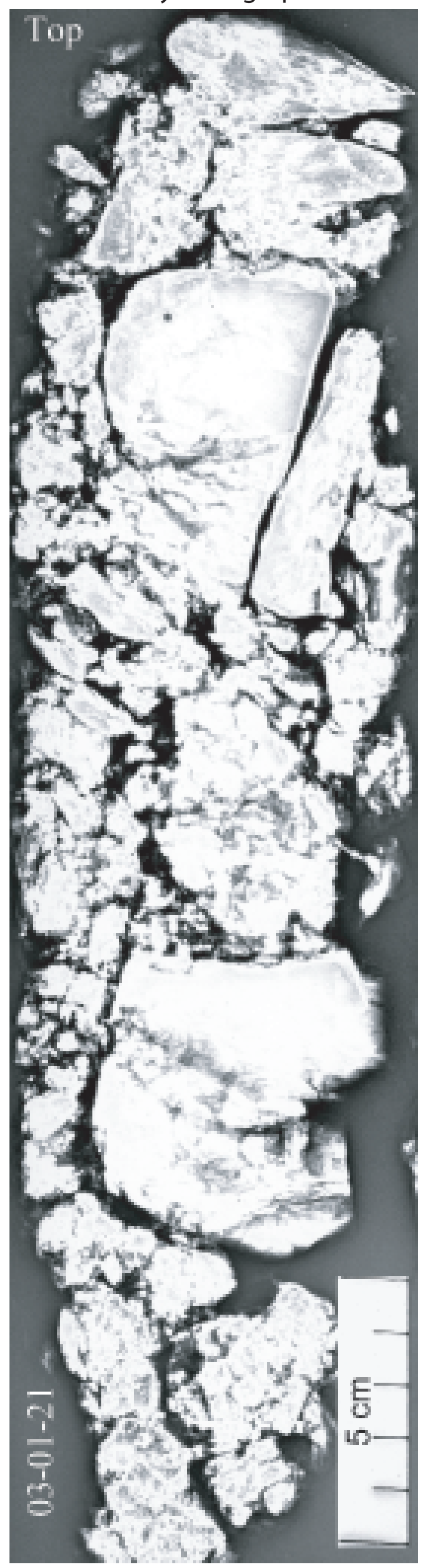

Carbonaceous shale, broken pieces 


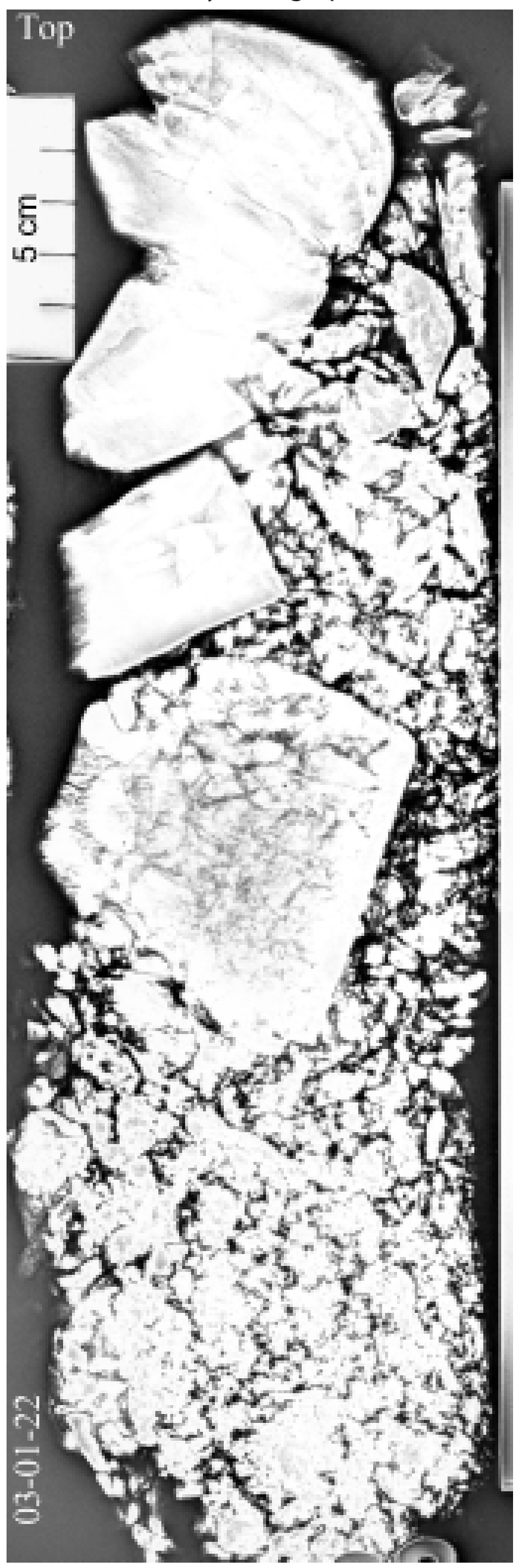

Carbonaceous shale, broken pieces 


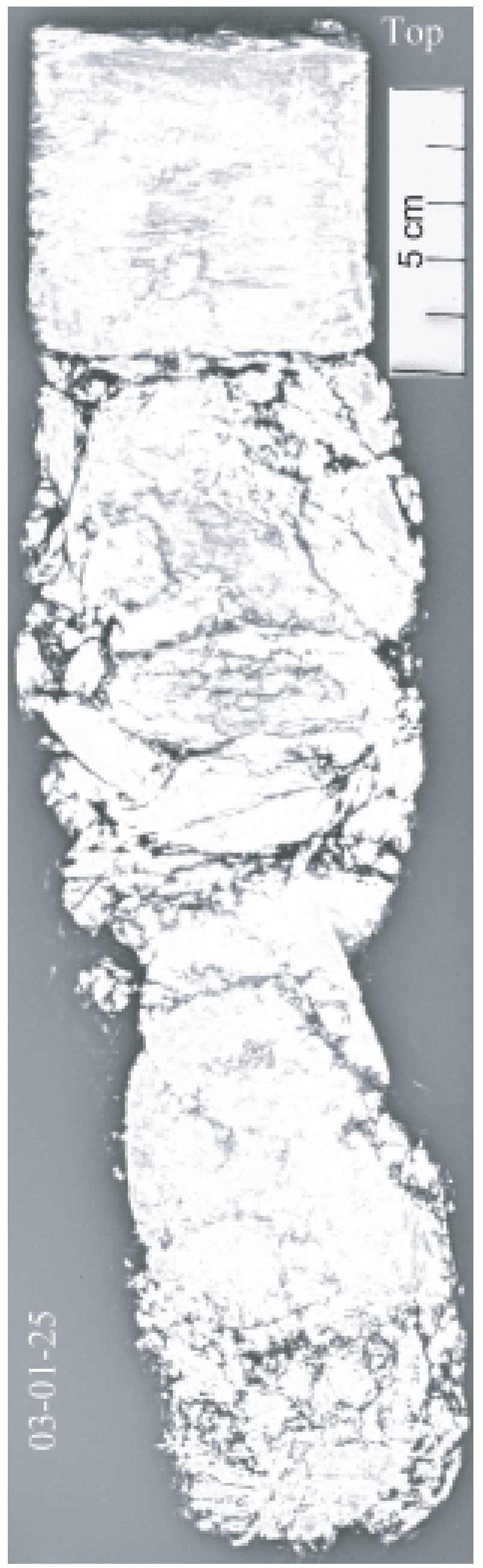

\section{Carbonaceous shale, broken pieces}


X-ray radiograph

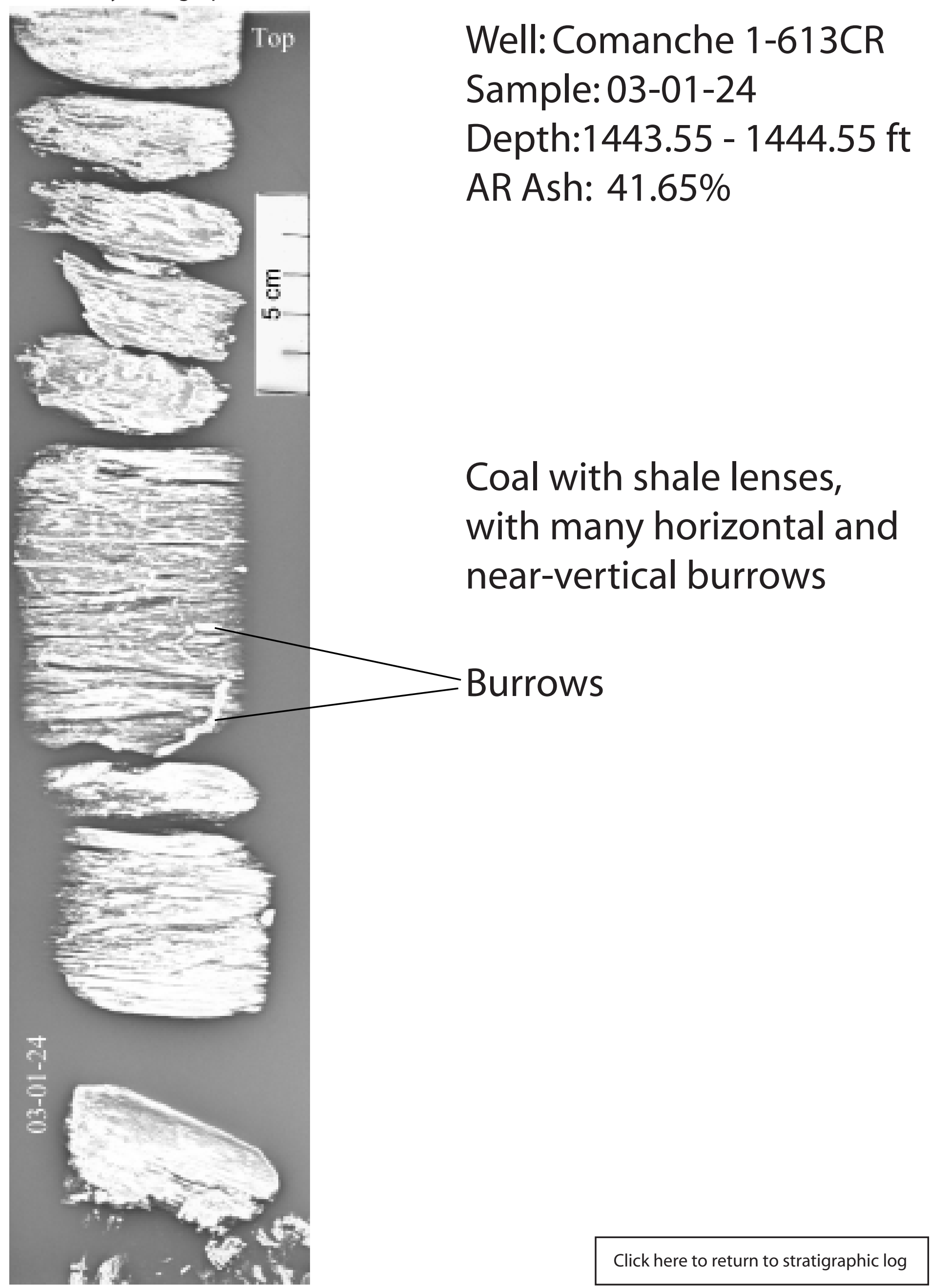




\section{X-ray radiograph}

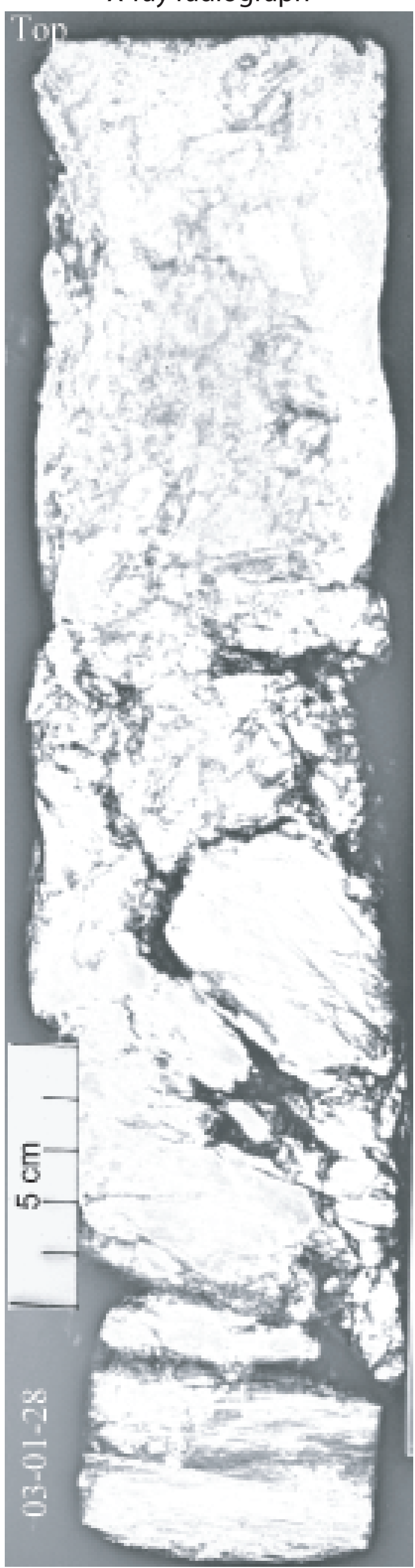

Well:Comanche 1-613CR

Sample:03-01-28

Depth:1452.20 - $1453.10 \mathrm{ft}$

AR Ash: $60.12 \%$

Carbonaceous shale, broken pieces 


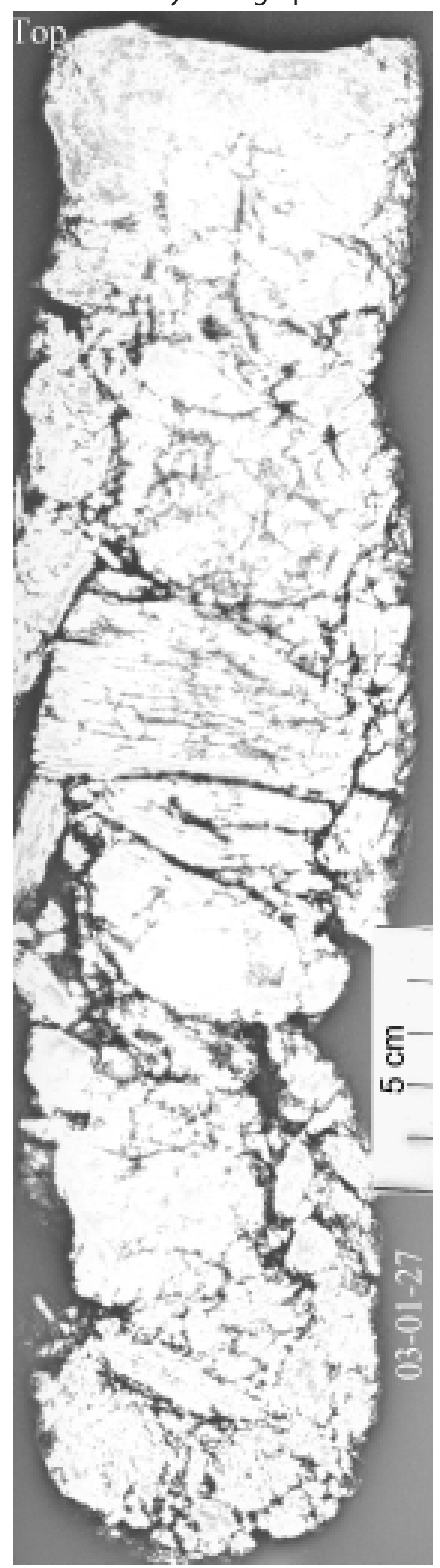

Carbonaceous shale, broken pieces 
X-ray radiograph

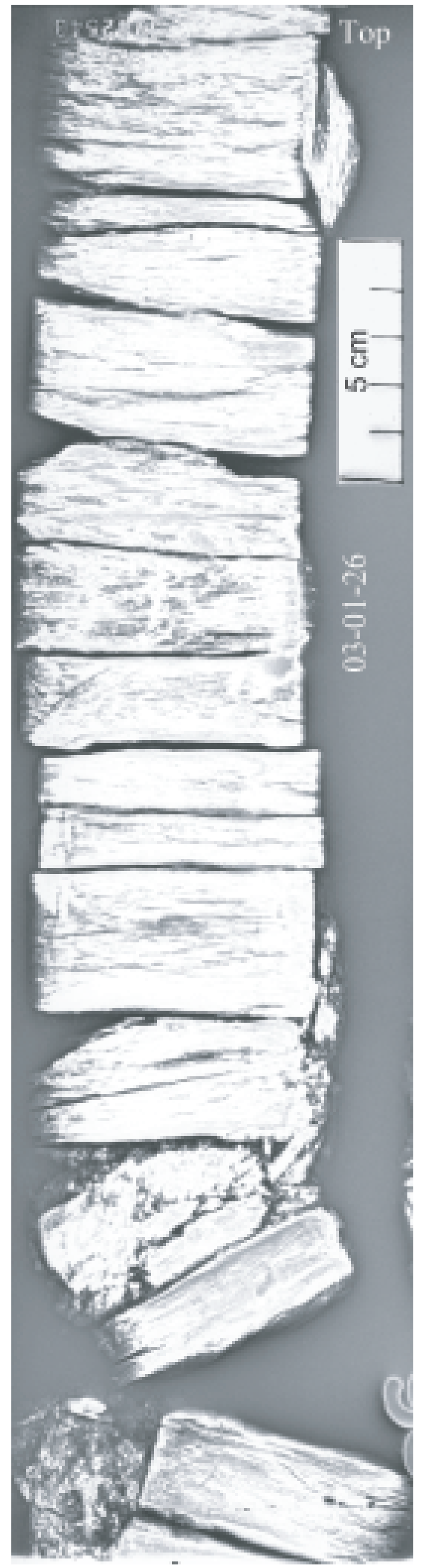

Carbonaceous shale, with coaly lenses and burrows 


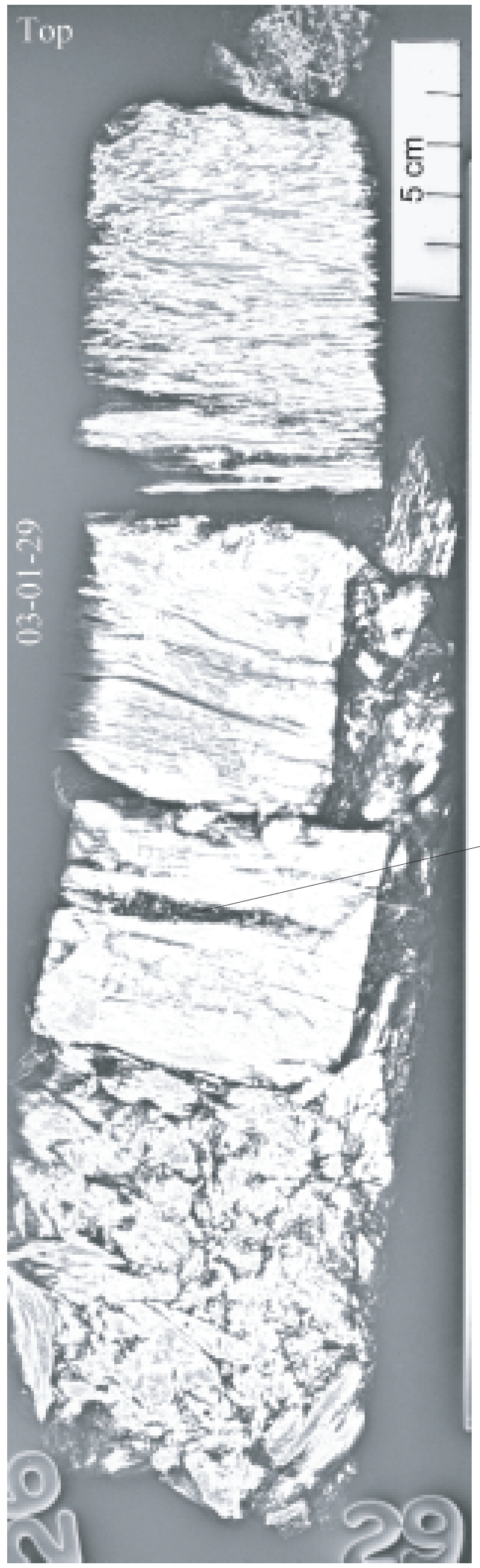

Carbonaceous shale, with coaly lenses and burrows

\section{Compressed woody lens, root?}


X-ray radiograph

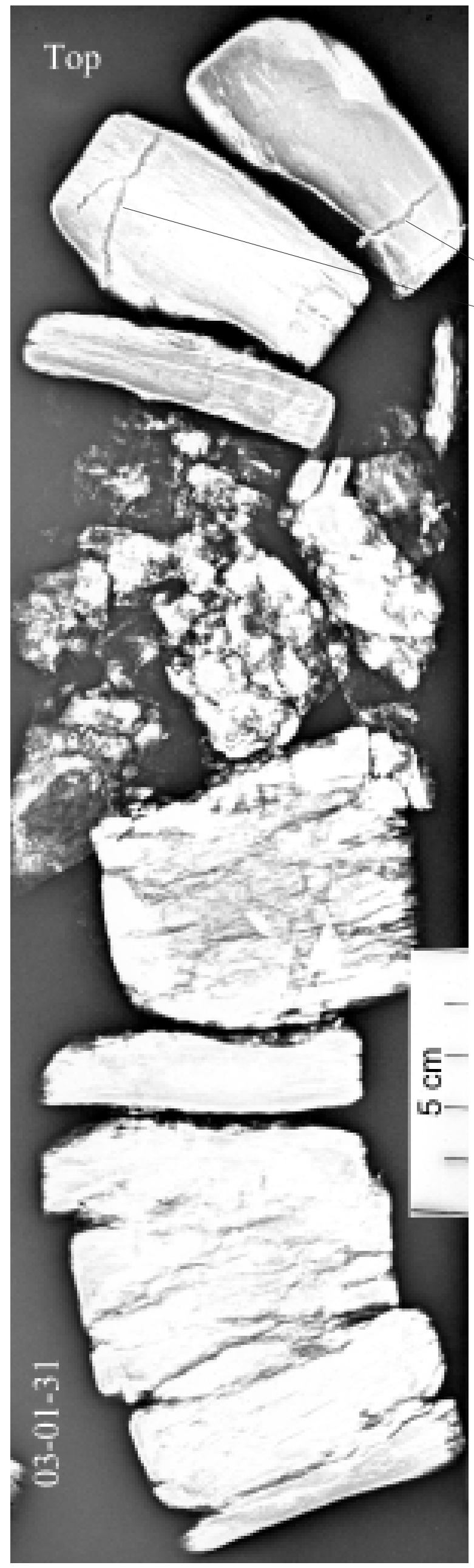

Well: Comanche 1-613CR

Sample: 03-01-31

Depth:1482.20 - $1483.20 \mathrm{ft}$

AR Ash: $65.69 \%$

Burrows, or roots (?)

Carbonaceous shale, with coaly lenses and burrows, broken pieces 
X-ray radiograph

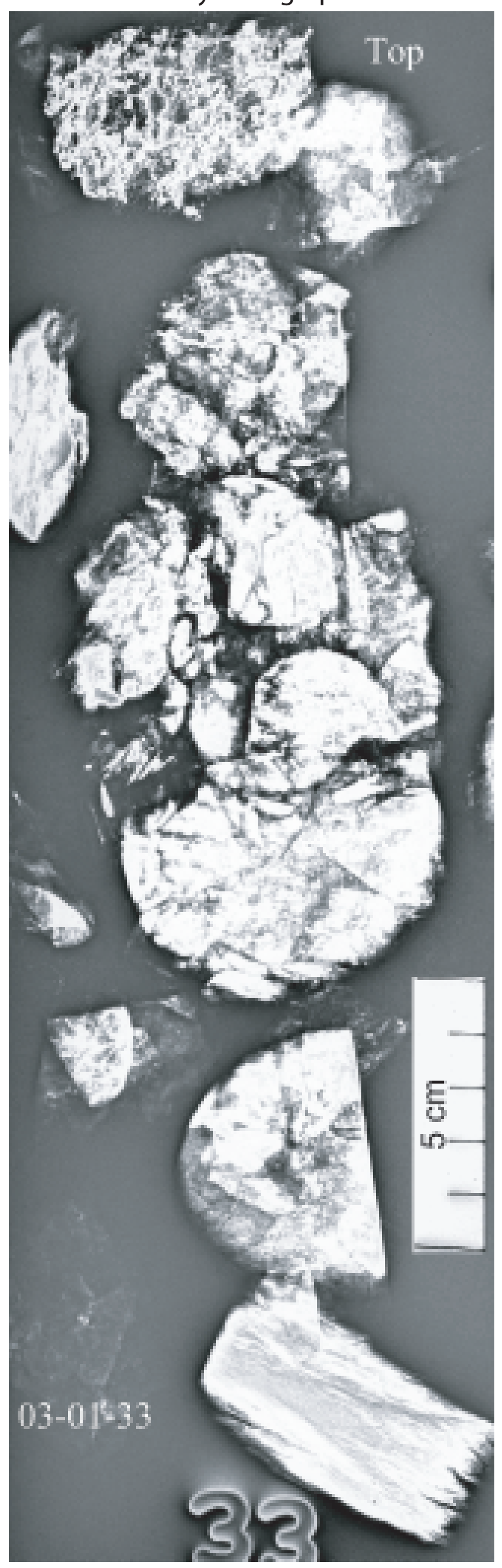

Carbonaceous shale, with coaly lenses and burrows, broken pieces 
X-ray radiograph

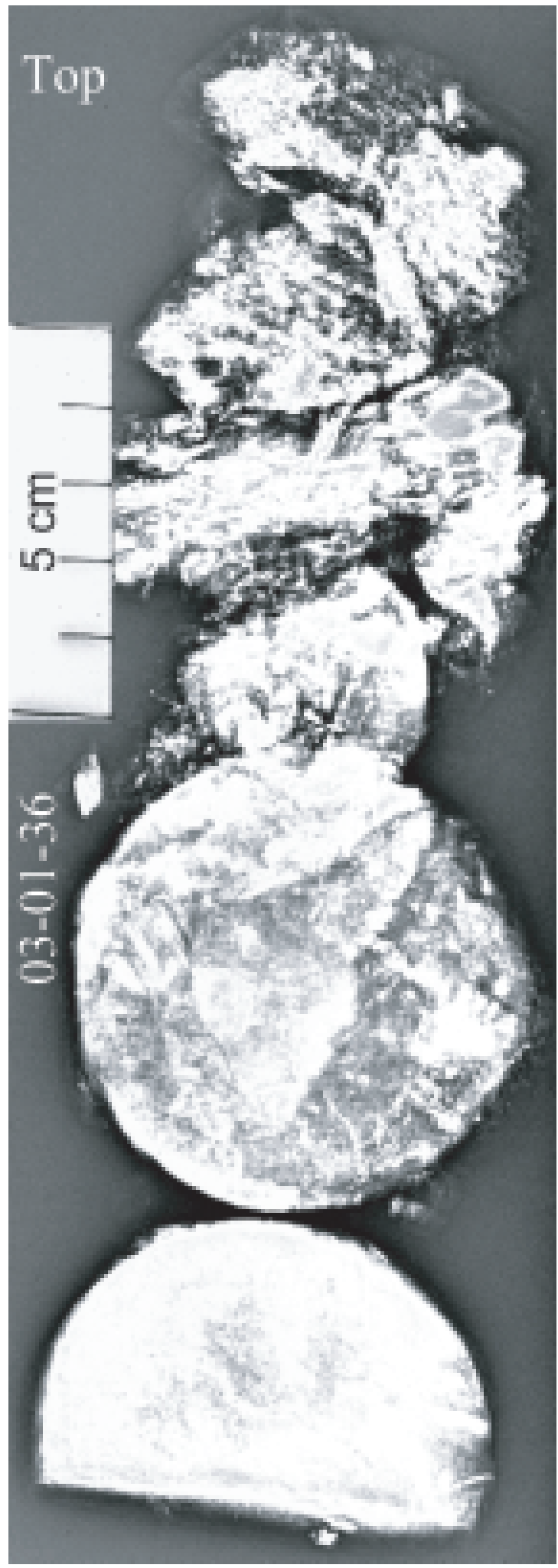

\section{Carbonaceous shale, broken pieces with coaly lenses and burrows}


X-ray radiograph

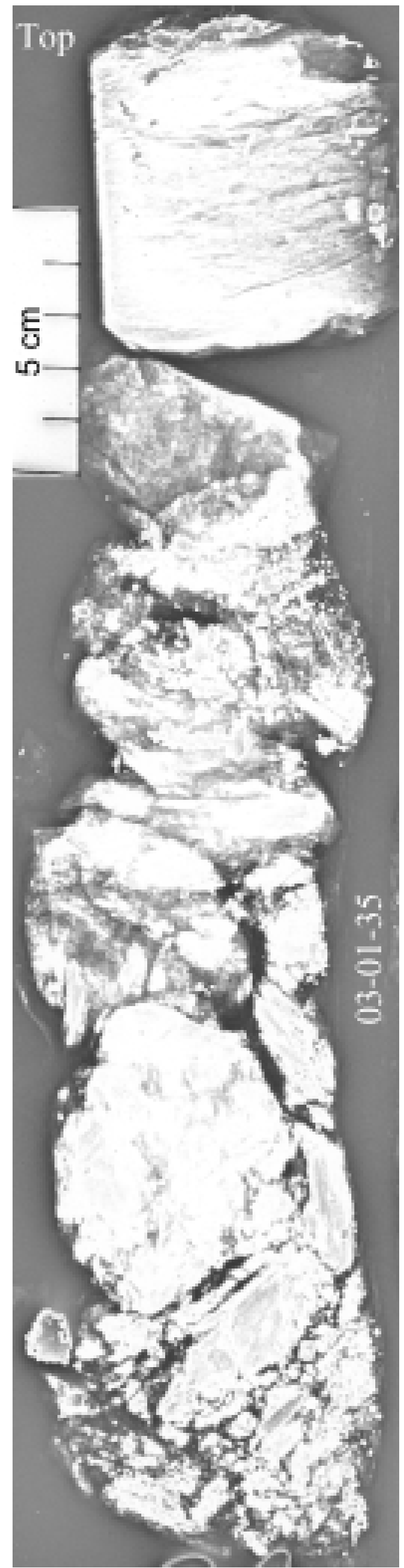

Well: Comanche 1-613CR Sample: 03-01-35

Depth:1503.65 - $1504.65 \mathrm{ft}$ AR Ash: $63.94 \%$

Carbonaceous shale, broken pieces with coaly lenses and burrows 


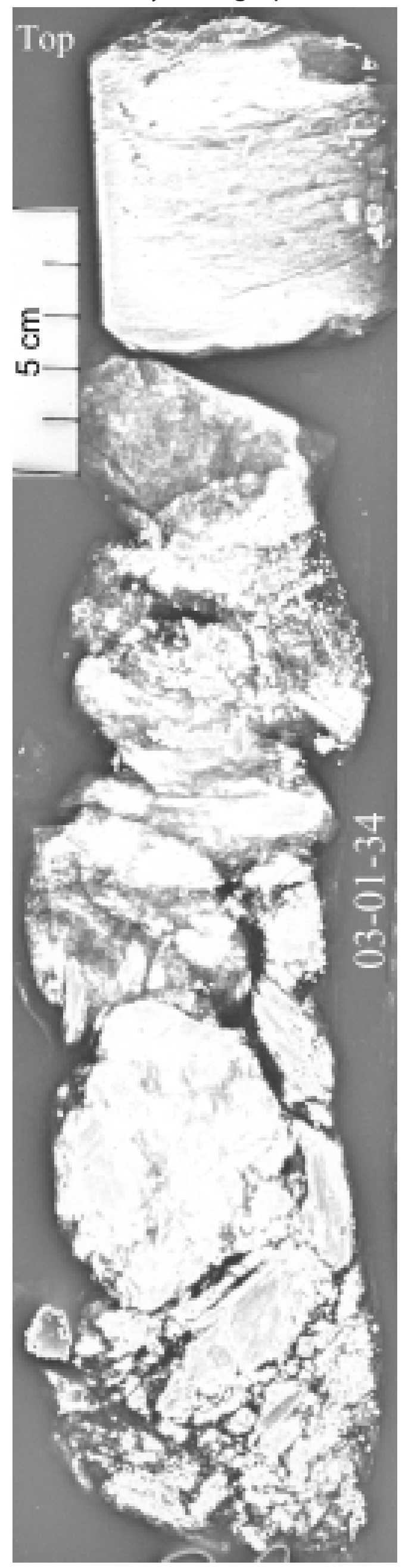

Carbonaceous shale, broken pieces with coaly lenses and burrows 


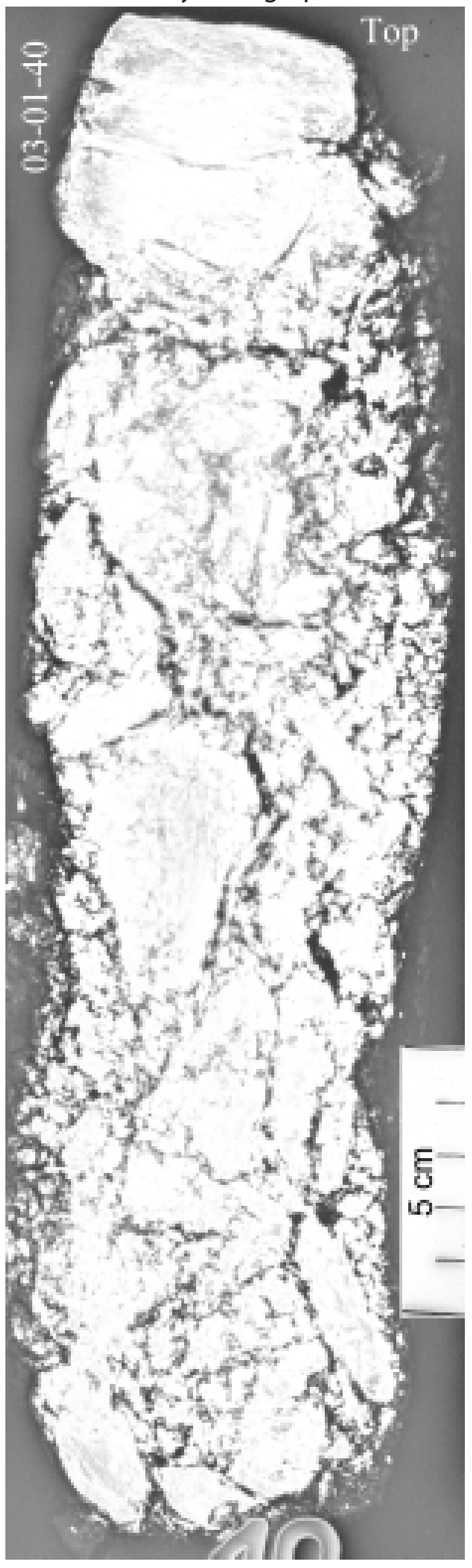

\section{Carbonaceous shale, broken pieces}


X-ray radiograph

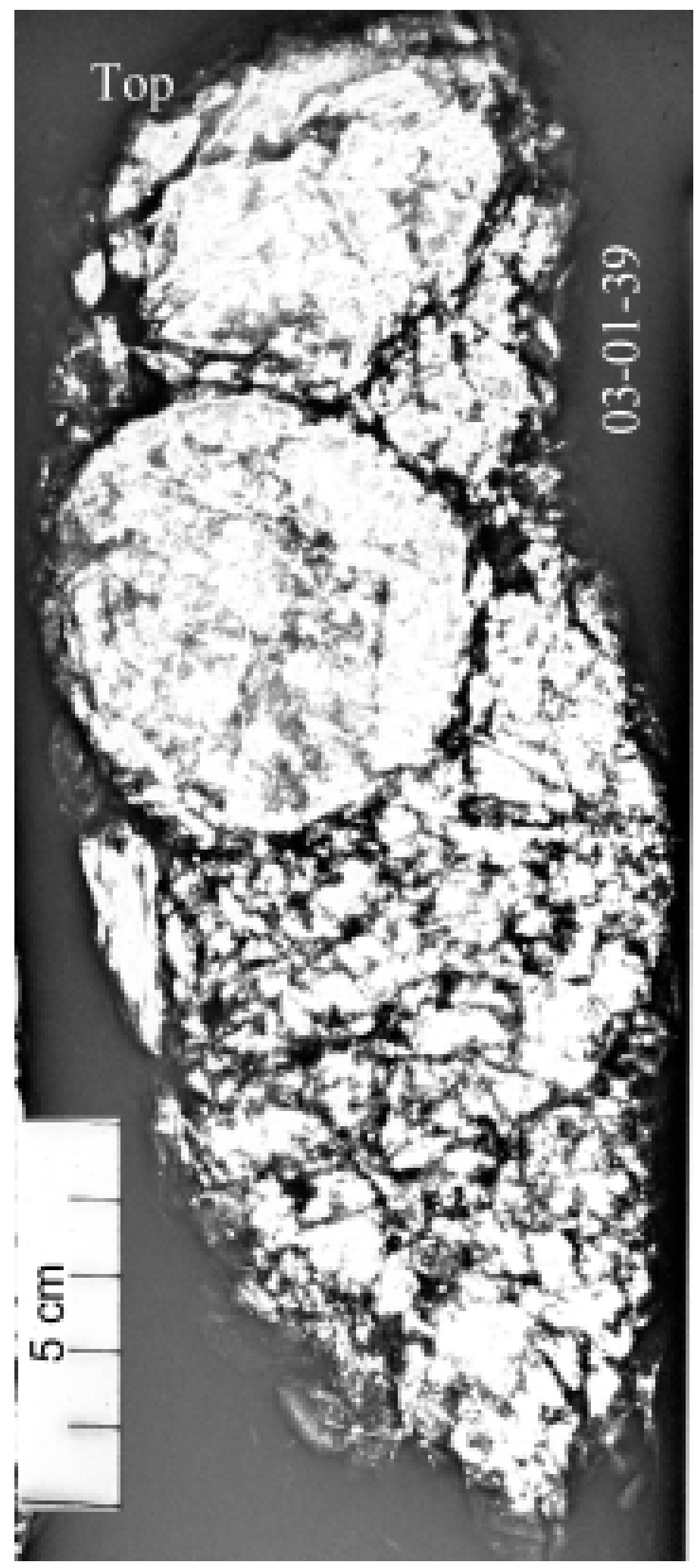

Well: Comanche 1-613CR

Sample: 03-01-39

Depth:1514.05 - $1514.50 \mathrm{ft}$ AR Ash: $48.77 \%$

\section{Carbonaceous shale, broken pieces}




\section{X-ray radiograph}

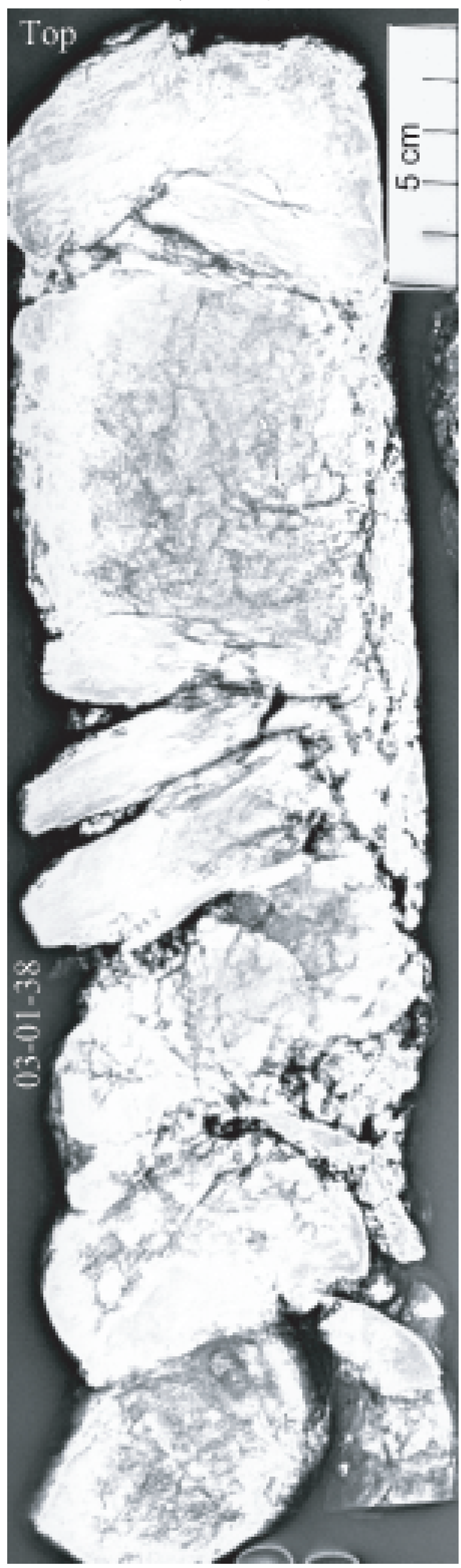

\section{Carbonaceous shale, broken pieces}




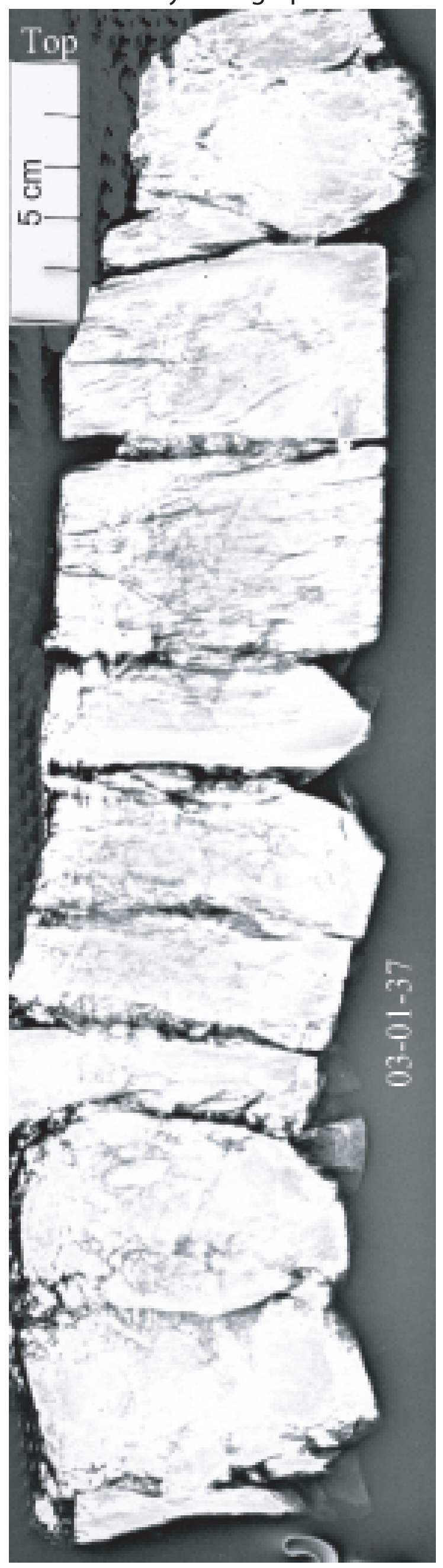

Carbonaceous shale, some coaly lenses 